\title{
Review \\ The Influence of Thermal Dilution on the Microstructure Evolution of Some Combustion-Synthesized Refractory Ceramic Composites
}

\author{
Sofiya Aydinyan ${ }^{1,2, *}$, Suren Kharatyan ${ }^{2}$ and Irina Hussainova ${ }^{1}$ (D) \\ 1 Department of Mechanical and Industrial Engineering, Tallinn University of Technology, Ehitajate 5, \\ Tallinn 19180, Estonia; irina.hussainova@taltech.ee \\ 2 Laboratory of Macrokinetics of Solid State Reactions, A.B. Nalbandyan Institute of Chemical Physics NAS RA, \\ P. Sevak 5/2, Yerevan 0014, Armenia; suren@ichph.sci.am \\ * Correspondence: sofiya.aydinyan@taltech.ee; Tel.: +372-5903-3365
}

Citation: Aydinyan, S.; Kharatyan, S.; Hussainova, I. The Influence of Thermal Dilution on the Microstructure Evolution of Some Combustion-Synthesized Refractory Ceramic Composites. Crystals 2022, 12, 59. https://doi.org/10.3390/ cryst12010059

Academic Editors: Vladislav V. Kharton and Pavel Lukáč

Received: 18 November 2021 Accepted: 30 December 2021 Published: 3 January 2022

Publisher's Note: MDPI stays neutral with regard to jurisdictional claims in published maps and institutional affiliations.

Copyright: (c) 2022 by the authors. Licensee MDPI, Basel, Switzerland. This article is an open access article distributed under the terms and conditions of the Creative Commons Attribution (CC BY) license (https:// creativecommons.org/licenses/by/ $4.0 /)$.

\begin{abstract}
Modeling the self-sustained high-temperature synthesis (SHS) reaction via thermal dilution and transformation of the reaction heterogeneous media into a moderate exothermic one has unlimited potential for designing inorganic powders of a certain morphology beneficial for advanced consolidation. Thermal/inert dilution of the high-exothermic mixtures leads to the fluent decrease of both the combustion temperature and velocity, thus allowing to tailor the thermal regime of the combustion process, therewith contributing to high yield of reaction and governing the microstructural features of the combustion products. In the current review, we shed on light on the possibilities of this effective strategy to control the thermal behavior of the SHS process for the preparation of applicable powder precursors for the subsequent successful sintering. Since the SHS process of some refractory ceramics $\left(\mathrm{MoSi}_{2}, \mathrm{TiB}_{2}, \mathrm{TiC}\right.$, etc.) involves a relatively violent reaction rate and high combustion temperature, achieving a high level of microstructure control in these systems is often challenging. The challenge was tackled with a thermal dilution approach, attaining considerable enhancement in the homogeneity among phases with an increase of diluent content along with microstructure refinement.
\end{abstract}

Keywords: self-propagating high-temperature synthesis; thermal dilution; combustion synthesis; refractory ceramics; sintering; microstructure; mechanical properties

\section{Introduction}

Self-propagating high-temperature synthesis (SHS) or combustion synthesis (CS) is one of the attractive but challenging approaches for the synthesis of advanced inorganic materials, including refractory ceramic-based composites [1,2]. After local ignition of the reactive mixture, the self-sustaining mode is achieved due to heat released at the chemical interaction converting reagents into products without the need for any external energy. In this scenario, the products' characteristics are primarily influenced by temperaturetime history of the reaction, which, in turn, accounts for thermodynamics, kinetics, and different physical phenomena associated with ignition of reaction [3-7]. Modeling the self-propagating high-temperature reactions with the aim of controlling the thermal regime of interaction involves different pathways, such as reactions coupling, inert dilution by reactants or products, heat losses, alteration of combustion wave propagation mechanisms, porosity, as well as thermal conductivity of the reactants and products, etc. [8,9]. By the same token, the modification of heterogeneous interaction medium (heat losses, porosity, inert dilution, etc.) will alter the demeanor of combustion wave propagation, and by changing the combustion parameters, one will influence on the products' microstructure. The critical role of dilution at combustion and microstructure formation mechanisms of some refractory ceramics (i.e., $\mathrm{Si}_{3} \mathrm{~N}_{4}, \mathrm{NbN}, \mathrm{VN}, \mathrm{AlN}$ ) [1,3,10-15] and ceramic composites [16-20] has already 
been demonstrated. The influence of porosity and thermal dilution on the combustion parameters and the combustion mode observed in Ti-C, Ta-C, and Ti-2B mixtures were comprehensively discussed in [21-24]. Smolyakov investigated the role of inert low melting additive in SHS processes from another stance [25] considering various combustion regimes induced by phase transformations, where the combustion wave propagation velocity is not conditional on the amount of inert diluent.

Thermal/inert dilution of the high-exothermic mixtures by one of the end-products [26-30] has been widely reported in terms of direct contribution to the temperature controlled self-sustaining process and wide potential for designing new systems with several advantageous properties, including improved degree of conversion, homogeneity, spherical shape, and uniform morphology. However, in the current review, we will focus on the possibilities of this effective strategy from another perspective, i.e., to control the temperature mode of the reaction for the fabrication of suitable powder precursors for successful sintering.

Compared to conventional manufacturing processes, in-situ spark plasma sintering allowed to overcome certain obstacles in powder processing, i.e., fine grain size and high density [31-34], and additive manufacturing (AM) through selective laser sintering [35-37] enabled the fabrication of near-net-shaped parts with great design freedom using refractory composites; however, the available feedstock is still limited. To design suitable precursors, the thermal dilution of the initial mixture is contemplated as a promising option, which tends to fluently reduce the combustion temperature and velocity, thus allowing to tailor the thermal mode of the combustion process and, simultaneously, govern the microstructural features of the combustion products that are vital for the consolidation processes. The design of novel systems by diluting exothermic mixture with one of the reactants may outline the general pathway of how to mitigate the explosive nature of self-sustaining processes and prepare suitable precursors for the sintering of bulks without the contamination of product.

In general, any deviation from the stoichiometry of the initial mixture decreases the combustion temperature based on a consideration of the reaction thermodynamics. The excess amount of reactants, in particular Si in Mo-Si system, Ti in Ti-B system, etc. will decrease the exothermicity of the reaction and the combustion temperature caused by a reduction in the heat released per unit mass of reactive mixture [38-43]. The addition of excessive amount of reactant as a diluent may sometimes act not only to control the reaction thermal mode, but also change the products' compositions (Ti excess in Ti $+2 \mathrm{~B}$ system may lead to the formation of $\mathrm{TiB}$ instead of $\mathrm{TiB}_{2}$ ). There are also two different phenomena that should be considered during the dilution of violent combustion reactions: temperature limit (combustion wave does not propagate due to high energy consumption by diluents) and concentration limit (no further improvement in the extent of conversion or product microstructure is observed). In this review, we aimed to demonstrate the effect of diluent or additive not on the combustion parameters, but on the microstructure evolution and sinterability of powders based on the available literature.

\section{Dilution Concept and Action Mechanism}

The dilution approach has garnered the interest of the scientific community owing to unlimited perspective of designing inorganic materials of certain morphology with plenty of advantageous features, including homogeneous distribution of phases, sphericity of particles, and uniform size distribution, that are beneficial for the advanced consolidation (spark plasma sintering, selective laser melting, etc.).

It was already established that finely dispersed powders of certain microstructure during SHS can be obtained with different methods, by decreasing combustion temperature, introducing modifiers, acting on the process or its products by shock wave or ultrasonic wave, or by fast cooling of a sample after the synthesis. Under the extreme conditions in combustion wave, destruction of the initial structure occurs so rapidly that the structure of equilibrium products have no time to be formed simultaneously with the process, the intermediates having different heat conductivity and heat capacities sequentially go 
through different temperature zones and the structurization proceeding behind the combustion front [44]. Varying the length of these zones (chemical reaction, post-combustion, cooling) through the dilution approach makes it possible not only to moderate thermal conditions, but also to contribute to high yield of reaction, controlled heating, and cooling rates, that are substantial for the fine and stable phase formation. The main requirements for the diluent are to be non-polluting and absorb the reaction heat effectively. The first condition is feasible if the diluent is removed effectively and easily after performing its function or if the diluent is the main product/one of the main products/constituents of the reaction. For example, alkali halides, as diluents, are soluble in water and can be removed by leaching [45,46], $\mathrm{MgO}$ is removed by acid leaching after reduction [30], $\mathrm{Al}_{2} \mathrm{O}_{3}$ usually is one of the constituents of target composite after the reduction process $[19,47,48]$ or, if necessary, it is leached by alkali solution, $\mathrm{NH}_{4} \mathrm{Cl}$ and $\mathrm{NH}_{4} \mathrm{~F}$ generally sublime to relatively low temperatures [49], etc. Metal chlorides are considered reliable diluting agents owing to their efficient heat absorption. For instance, the heat capacity of $\mathrm{NaCl}$ is $50 \mathrm{~J} /(\mathrm{mol} \cdot \mathrm{K})$, and due to sensible and latent heat, it effectively lowers the adiabatic temperature. In addition to decreasing the adiabatic temperature, they have the ability to stabilize the combustion reaction, moderate explosion reactions, decrease combustion velocity and combustion temperature, and, as a result, inhibit the grain growth and agglomeration. Moreover, different morphologies can be obtained in the products according to the type and amount of diluents used. Another mechanism of action is changing the transport properties throughout the synthesis reactions; for instance, when diluent sublimes at relatively low temperatures and produces a fluffiness effect, it is shown to be very beneficial for the nitridation processes [49]. When the diluent is molten, the diffusion rates of the reaction ions increase and promote the complete conversion, provide a controlled cooling environment (homogeneous, without thermal gradients, chemically inert) for the product, and maintain a moderate cooling process, which facilitates the regulation over the phase composition and morphology of the powder produced. Molten salts have been shown to enhance the diffusion of reactants at comparatively lower temperature than the conventional reaction temperature and prevent oxidation. The presence of diluent is also of extreme importance for the metallothermic reactions (aluminothermy, magnesiothermy), which are violent reactions in nature $[19,30]$. The dilution of thermite type reactions by aluminum, magnesium, or alumina lowers the combustion temperature; however, usually the action mechanism is not a simple absorption of energy. As it was demonstrated in [50], aluminum behaves not only as a diluting agent but also as an intermediate phase taking part in the combustion reaction of the Al-Ti-C system for the fabrication of Al-matrix composites reinforced with TiC. The increase in aluminum amount in the initial mixture tend to prolong the ignition delay duration and lower the combustion temperature; as a result, TiC particle size was decreased 5 times and intermediate $\mathrm{TiAl}_{3}$ phase reacts with $\mathrm{C}$ forming $\mathrm{TiC}$.

In the current review, the possibilities of thermal dilution strategy to control the thermal regime of the combustion process for the synthesis of applicable powder precursors for the subsequent successful sintering are discussed on the example of some refractory ceramics $\left(\mathrm{MoSi}_{2}, \mathrm{TiB}_{2}, \mathrm{TiC}\right.$, etc.), that involve violent combustion conditions at their synthesis and are difficult to control the homogeneity among sample phases and microstructure features.

\subsection{Molybdenum Disilicide-Silicon System}

$\mathrm{MoSi}_{2}$ has already demonstrated its valuable potential for extremely high temperature structural applications. Shaping $\mathrm{MoSi}_{2}$ into intricate geometries and therewith wider application is contracted by its brittleness. The approach to overcome this is the fabrication of $\mathrm{MoSi}_{2}$ samples via SLM of $\mathrm{MoSi}_{2} / \mathrm{Si}$ powder of core-shell morphology. The silicon shell may compensate the poor laser absorptivity of ceramic phase and act as a binder, while the ceramic core has to provide mechanical durability. $\mathrm{MoSi}_{2} / \mathrm{Si}$ powder was combustion synthesized and subjected to densification by SLM generating bulk cylindrical shapes and lattice structures. The latter was further subjected to functionalization in a nitrogen 
atmosphere. The preparation pathway of $\mathrm{MoSi}_{2} / \mathrm{Si}$ bulks and lattices through SLM and their conversion into $\mathrm{MoSi}_{2}-\mathrm{Si}_{3} \mathrm{~N}_{4}$ fully ceramic composite was manifested [38].

Thermodynamically, the formation of $\mathrm{MoSi}_{2}$ from the stoichiometric mixture of elements is an exothermic process $(\Delta \mathrm{H}=-130 \mathrm{~kJ} / \mathrm{mol})$ with adiabatic temperature of $1650{ }^{\circ} \mathrm{C}$ enough to react in combustion mode. The increasing of silicon amount $>2$ mole has a thermal dilution effect, as it absorbed the heat liberated in the Mo $+2 \mathrm{Si}$ interaction and led to the fluent decline in combustion temperature and formation of $\mathrm{MoSi}_{2}$ phase along with silicon from the Mo-nSi reactive mixture. According to microstructural features, different mechanisms of $\mathrm{MoSi}_{2}$ formation (solid-solid and solid-liquid reactions) were engaged (Figure 1). Molybdenum dissolves in silicon melted at combustion temperature followed by $\mathrm{MoSi}_{2}$ grain precipitation. In parallel, $\mathrm{MoSi}_{2}$ formation and growth occur by a reactive diffusion mechanism, indicating the evolution of comparatively small particles of $\mathrm{MoSi}_{2}$ (Figure 1a,b adopted from [38]). As a result, SHSed powder comprises ceramic grains of $<4 \mu \mathrm{m}$ in size bordered by silicon layer at $\mathrm{n}(\mathrm{Si})=2.2$. The silicon fuses and homogeneously covers grains of ceramic phase evincing that the solid-liquid interaction between Mo and Si prevails (Figure 1c) and create a profound ground for subsequent sintering. At $\mathrm{n}=3 \mathrm{~mol}$, the combustion does not proceed in a self-sustaining mode and combustion limit is observed. The reason behind this is the higher amount of silicon ( $n>2$ moles) playing a role of an inert diluent and decreasing the combustion temperature. According to thermodynamic calculations by ISMAN-THERMO software, the interaction proceeds as follows: $\mathrm{Mo}+3 \mathrm{Si}=\mathrm{MoSi}_{2}(\mathrm{~s})+\mathrm{Si}(\mathrm{s})$, with a combustion temperature of $1560 \mathrm{~K}$, which is significantly lower than the melting point of silicon, whereas the interaction in the mixture of molybdenum and silicon was proven to propagate in the combustion mode in the presence of liquid phase via a solid (molybdenum)-liquid (silicon) mechanism.
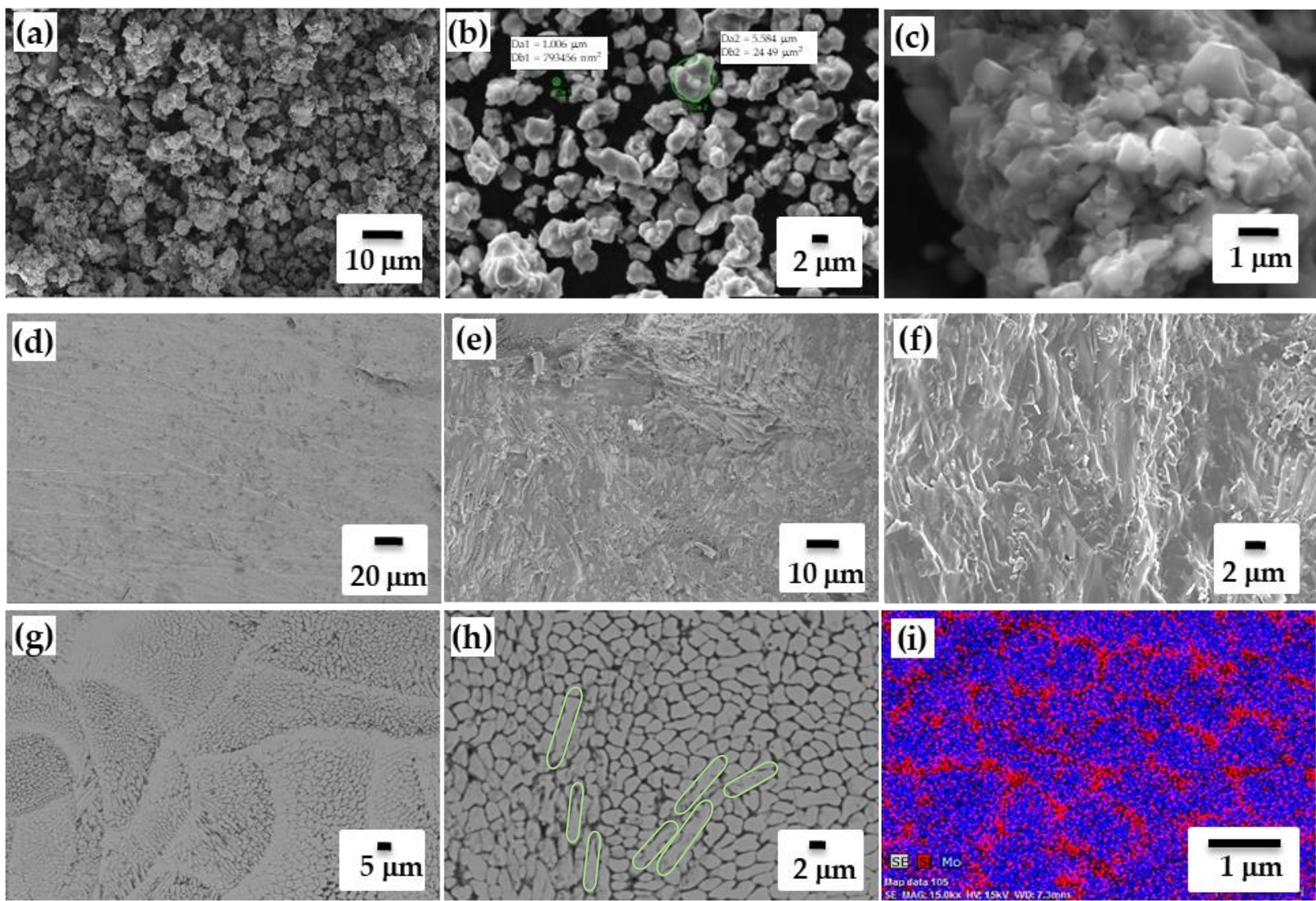

Figure 1. SEM images of $\mathrm{MoSi}_{2}-10$ wt.\% Si powder (a-c); SEM images of the surface (d,g,h); and cross-section (e,f) with different magnifications, EDS mapping of surface (i). 
Selective laser sintering of pure $\mathrm{MoSi}_{2}$ produced fragile structures, but SLS of $\mathrm{MoSi}_{2}-\mathrm{Si}$ composites leads to compacts of up to $92 \%$ relative density. The mechanical properties and relative density were strongly dependent on the laser energy density (LED) and silicon amount. The sintered bulks exhibit higher relative density at higher LED caused by lower viscosity of Si and better distribution throughout the ceramic particles. Meanwhile, the high amount of silicon ( 2.6 and 2.8 moles) drastically changes the relative density of the parts (toward an increase) regardless of the LED, caused by comparatively better laser absorptivity of silicon compared to $\mathrm{MoSi}_{2}$ phase. The consolidation of powders with lower silicon content ( 2.2 and 2.4 moles) led to the formation of cracks, pores, and defects, as the amount of silicon is not enough to homogeneously encompass the ceramic core. With an increase in the silicon amount up to $2.8 \mathrm{~mol}$, the thermal stresses are reduced and result in the formation of crack-free parts, comprising a smoother surface in contrast to the Si-lean counterparts. The increase of the laser current facilitates the sintering and positively influences the hardness; however, as it was expected, the increase in silicon amount tended to decrease the hardness caused by increase in the portion of the "soft" phase. Previously reported data of hardness for the $\mathrm{MoSi}_{2}$-based ceramic composites consolidated by other methods (vacuum hot pressing, hot isostatic pressing, etc.) are inferior to hardness values recorded as 9.5-11.4 GPa for SLM-sintered $\mathrm{MoSi}_{2}-\mathrm{Si}$ composite. For instance, laser surface melted $\mathrm{MoSi}_{2}-\mathrm{Mo}_{5} \mathrm{Si}_{3}$ eutectic single crystals exhibit hardness from $11.60 \pm 0.04 \mathrm{GPa}$ (substrate) to $15.96 \pm 0.42 \mathrm{GPa}$ [51]. In spite of the fact that the relative density of the $\mathrm{MoSi}_{2}$-Si samples after SLM was not high enough, the improved strength and moderate hardness were achieved thanks to the specific SLM texture.

Concave-shaped lines correspond to a laser track and they separate adjacent sections approximately by the scan spacing length (Figure 1d). As we can see, the melt pools with a half-ellipse shape was observed (Figure 1g) with mono-modal cellular microstructure of silicon shell (dark or rose) and $\mathrm{MoSi}_{2}$ core (bright or blue) (Figure 1h,i) of 1-2 $\mu \mathrm{m}$ average size of cells in well compliance with the particles of initial powder. The development of elongated cells from the melt pool is seen from the surface SEM images (Figure 1h). For many metallic materials and silicon-containing alloys, the tendency of elongated columnar cells perpendicular to the melt-pool boundary and toward the maximum heat flow direction was observed [52]. From the cross-sectional analysis script-lamellar structure is clearly seen and how columnar cells tend to grow perpendicular to scanning/building direction. The influence of directional scanning on the surface and cross-sectional textures is also in accordance with crystallographic texture of $\mathrm{MoSi}_{2}$ phase comprising C11b-type tetragonal lattice structure.

From SHS-derived $\mathrm{MoSi}_{2}$ with silicon diluted systems, lattice structures were also successfully produced [53]. The scanning speed was fixed to $80 \mathrm{~mm} \mathrm{~s}^{-1}$ and the laser current was altered from 1000 to $4000 \mathrm{~mA}$ (corresponding to LED from 200 up to $800 \mathrm{~J} \mathrm{~mm}^{-3}$ ). When using low lower laser current $(<1000 \mathrm{~mA})$, the developed lattices are fragile, but increase in the laser current up to I $=4000 \mathrm{~mA}$ caused Maragoni flow and splashing due to overheating of local areas. The process window aimed at receiving the designed lattice structures was determined to be very narrow according to scan velocity and LED values. The strong influence of the laser power on the strut-diameter of the lattices was revealed. With increase in the current up to $3000 \mathrm{~mA}$, the silicon melts and acts as a binder phase originating neck connections between ceramic particulates and contributing to the construction of 3D porous structures. Cross-sectional analysis of the sample showed that grain boundaries are hardly noticeable due to good sintering of $\mathrm{MoSi}_{2}$ and $\mathrm{Si}$ phases whereas some amount of $\mathrm{Mo}_{5} \mathrm{Si}_{3}$ phase was also detected by XRD analysis (Figure 2c). The presence of sections with long columnar grains of $\mathrm{MoSi}_{2}$ might be explained by the Si diffusion along the $\mathrm{MoSi}_{2}$ boundaries and reaching the $\mathrm{Mo}_{5} \mathrm{Si}_{3} / \mathrm{MoSi}_{2}$ interface. 

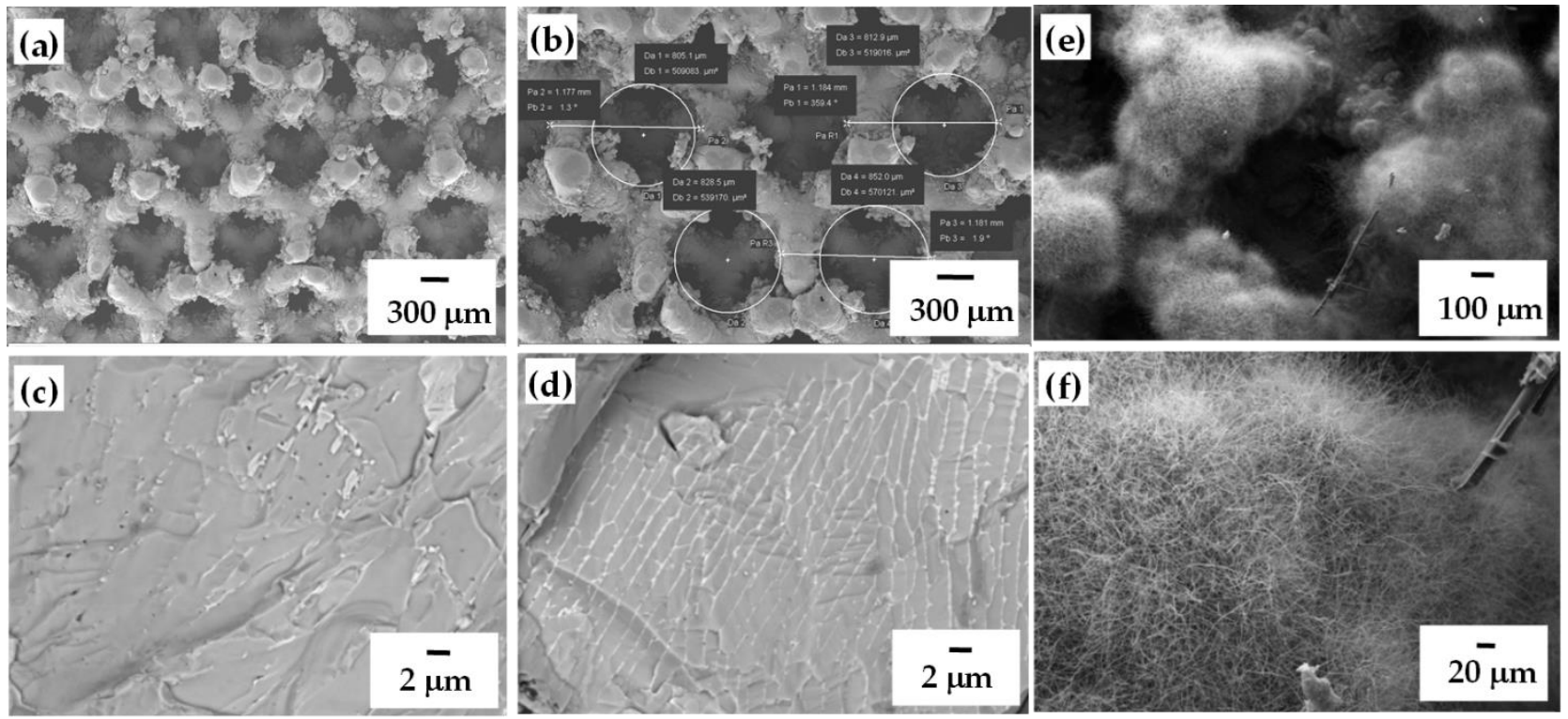

Figure 2. SEM image of SLMed $\mathrm{MoSi}_{2} / \mathrm{Si}$ lattice at $\mathrm{I}=3500 \mathrm{~mA}$ with different magnifications $(\mathbf{a}, \mathbf{b})[36])$, cross section of the wall $(\mathbf{c}, \mathbf{d})$; single cell preview after nitridation $(\mathbf{e}, \mathbf{f})$.

Usually, $\mathrm{MoSi}_{2}$ is fractured transgranularly at room temperature, but the Si-containing alloys fractured intergranularly. As it can be distinguished from the Figure $2 \mathrm{c}, \mathrm{d}$, the $\mathrm{MoSi}_{2}-\mathrm{Si}$ structure has both transgranular cleavage and some intergranular fracture, probably attributed to the presence of $\mathrm{Mo}_{5} \mathrm{Si}_{3}$ phase on the $\mathrm{MoSi}_{2} / \mathrm{Mo}$ interface [54]. The further nitridation of the lattices demonstrated decrease in the portion of volume defects from 0.9 to $0.3 \%$ and increase in compressive strain as compared to untreated lattices due to $\mathrm{Si}_{3} \mathrm{~N}_{4}$ formation on the surface (the volume was free of $\mathrm{Si}_{3} \mathrm{~N}_{4}$ ) (Figure 2e,f) [36] indicating the concentration of defects mainly on the cell's surface. Taking into consideration the properties of the lattices from $\mathrm{MoSi}_{2}$-based composites containing $10-13 \mathrm{wt} . \%$ of silicon as a binder produced by SHS and sintered by SLM technique in a single step is assumed to be perspective for heat exchangers and tissue engineering [55].

\subsection{Molybdenum Disilicide-AlSi10Mg Alloy System}

The SLM process was utilized to prepare high density $\mathrm{Mo}\left(\mathrm{Si}_{1-x}, \mathrm{Al}_{\mathrm{x}}\right)_{2}$ based composites of hardness exceeding $500 \mathrm{HV} 1$ from the mixture of combustion synthesized $\mathrm{MoSi}_{2}$ powder and $\mathrm{AlSi} 10 \mathrm{Mg}$ alloy. $\mathrm{MoSi}_{2}$ represented 1-5 micron-sized particles with frequent agglomerates (D50 $=18 \mu \mathrm{m}$ ) and AlSi10Mg alloy contained satellite particles of spherical and occasional morphology with Gaussian size distribution concentrated on $38 \mu \mathrm{m}$. The surface finish and chemical and microstructural homogeneity of the coupons produced at both 150-200 W laser power and $400-500 \mathrm{~mm} \cdot \mathrm{s}^{-1}$ scan speed and at $250 \mathrm{~W}$ laser power and $700 \mathrm{~mm} \cdot \mathrm{s}^{-1}$ scan speed were admissible. Relatively low roughness for the horizontal and vertical surfaces indicated the fair quality of the sintered parts. The microstructure evolution of an SLM-fabricated $\mathrm{MoSi}_{2}-\mathrm{AlSi} 10 \mathrm{Mg}$ part exhibits a characteristic scalloped structure pattern due to fast melting and rapid solidification in the direction of the laser (Figure 3). Each scallop comprises fine columnar dendritic structures and elongated grains with a fine divorced cellular structure $(\sim 1 \mu \mathrm{m})$. The formation of this unique structure occurs during the interaction of material with laser. Fine columnar dendrites of hexagonal $\mathrm{Mo}\left(\mathrm{Si}_{1-\mathrm{x}}, \mathrm{Al}_{\mathrm{x}}\right)_{2}$ ceramic encircled by hypoeutectic $\mathrm{Al} 0 .{ }_{.85} \mathrm{Si}_{0.15}$ phase are formed; simultaneously, the substituted Si fuses, dissolves, and precipitates at grain boundaries, collapsing the cellular structure and ripening the overall microstructure [56,57]. The size and distribution of nanosized precipitates and cellular structures have a profound effect on mechanical properties, as demonstrated by the enhanced microhardness of the samples ( 600 HV1). 


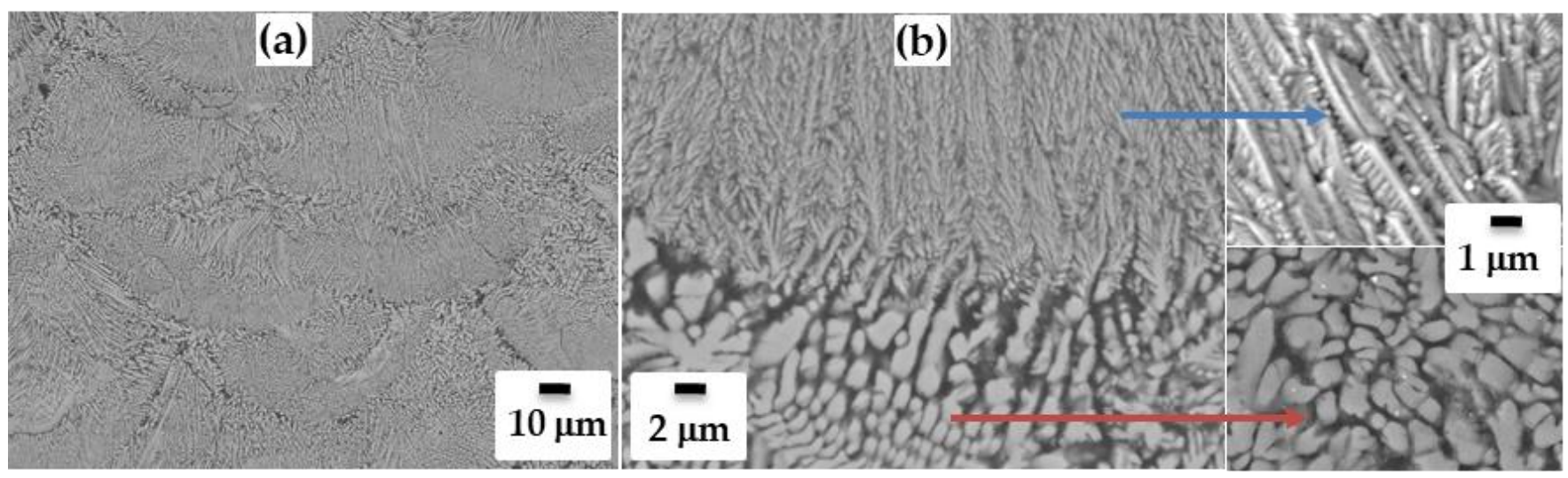

Figure 3. SEM images of fracture of SLM-ed compact from SHSed MoSi ${ }_{2}-30$ wt.\%AlSi10Mg alloy mixture at different magnifications $(\mathbf{a}, \mathbf{b})$.

\subsection{Titanium Diboride-Silicon System}

The preparation of $\mathrm{TiB}_{2}$-Si composites by SHS technique from the exothermic interaction in the Ti-B-Si mixture is detailed in [39]. It concerns the spark plasma sintering (SPS) procedure at relatively low temperatures and successful selective laser sintering of $\mathrm{TiB}_{2}$-Si ceramic based composite material. The SHS process was preliminary designed by thermodynamic modeling and optimized by combustion experimental procedure. $\mathrm{TiB}_{2}-\mathrm{Si}$ ceramic-metalloid feedstock of "pomegranate-like" structure has been pioneered and adjusted for selective laser melting (SLM) [39].

The interaction in Ti-B mixture is characterized by a very high adiabatic temperature $\left(\mathrm{T}_{\mathrm{ad}}=3500^{\circ} \mathrm{C}\right)$. For the preparation of $\mathrm{TiB}_{2}-\mathrm{Si}$ ceramic powder in the combustion mode, a moderate exothermic interaction of the $\mathrm{Ti}+2 \mathrm{~B}+\mathrm{xSi}$ mixture was utilized. The possibility of formation of $\mathrm{TiB}_{2}$ and silicon was thermodynamically predicted and the diagram was constructed according to silicon amount in the initial mixture [58]. The silicon content $(x)$ changed from 0 up to $4 \mathrm{~mol}$ in a wide temperature zone of $1200-2800{ }^{\circ} \mathrm{C}$. The SHS of $\mathrm{TiB}_{2}-\mathrm{Si}$ composite powder, namely the formation of ceramic $\mathrm{TiB}_{2}$ particles enveloped by silicon melt, was thermodynamically evaluated to be feasible at silicon amount of 1-2 moles. Note that $\mathrm{Si}$ takes part as an inert diluting agent. Up to a certain amount of silicon, it has no direct involvement in the self-propagating combustion reaction but leads to smooth decrease in combustion parameters $\left(\mathrm{U}_{\mathrm{c}}, \mathrm{T}_{\mathrm{c}}\right)$ and provides enough liquid $\mathrm{Si}$ for coating $\mathrm{TiB}_{2}$ particulates. The combustion process in the mixtures with up to $\mathrm{n}(\mathrm{Si})=2.75$ moles was terminated as silicon occupied $63 \mathrm{vol} . \%$ of the mixture under study. The packing geometry of the particles in the mixture allow to presume that silicon particles are mostly responsible for the heat transfer between the reactants interface upon the SHS reaction, so its low conductivity may result in heat transfer hurdles and consequent termination of the combustion reaction. The combustion temperature was shown to be very sensitive also to the change in sample dimensions. Pilot batches $(\mathrm{m}=500 \mathrm{~g})$ were characterized by combustion temperature close to the melting temperature of $\mathrm{Si}\left(\mathrm{T}_{\mathrm{C}}=1420-1450{ }^{\circ} \mathrm{C}\right)$ and resulted in the evolution of finer $\mathrm{TiB}_{2} / \mathrm{Si}$ particles compared with smaller samples of $20 \mathrm{~g}\left(\mathrm{~T}_{\mathrm{C}}=1500-1600{ }^{\circ} \mathrm{C}\right)$. Moreover, longer dwell time (about $1 \mathrm{~min}$ ) was observed at a maximum temperature in contrast to small samples (only few seconds) providing an advantageous environment for interaction completion in the post-combustion zone.

The silicon content up to 2 moles, stoichiometric quantities of Ti and B, along with the combustion temperature $T_{\mathrm{C}}$ above the melting point of silicon were determined to be optimum for the preparation of $\mathrm{TiB}_{2} / \mathrm{Si}$ composite material with ultra-fine ceramic particles glued by silicon melt.

The evolution of combustion front underwent changes by the presence of silicon, progressing from the top of the sample to bottom with an undulating movement, whereas the smooth planar combustion wave is typical for the Ti-B mixtures. Increasing the amount of silicon diluent decreases the combustion temperature, the wave propagation becomes 
unstable and leads to layered structure evolution in the product. According to SEM images, the milled product from the Ti-2B-nSi mixtures $(n=1.5-2$ moles $)$ represents a collection of particles and agglomerates, $<50 \mu \mathrm{m}$ and $\sim 0.1 \mathrm{~mm}$ in size, respectively. They are called "pomegranate-like" particles: a collection of fine ceramic particulates "glued" together by $\mathrm{Si}$. The diameters of the particulates were in the $200-450 \mathrm{~nm}$ range (Figure $4 \mathrm{a}, \mathrm{b}$ ).
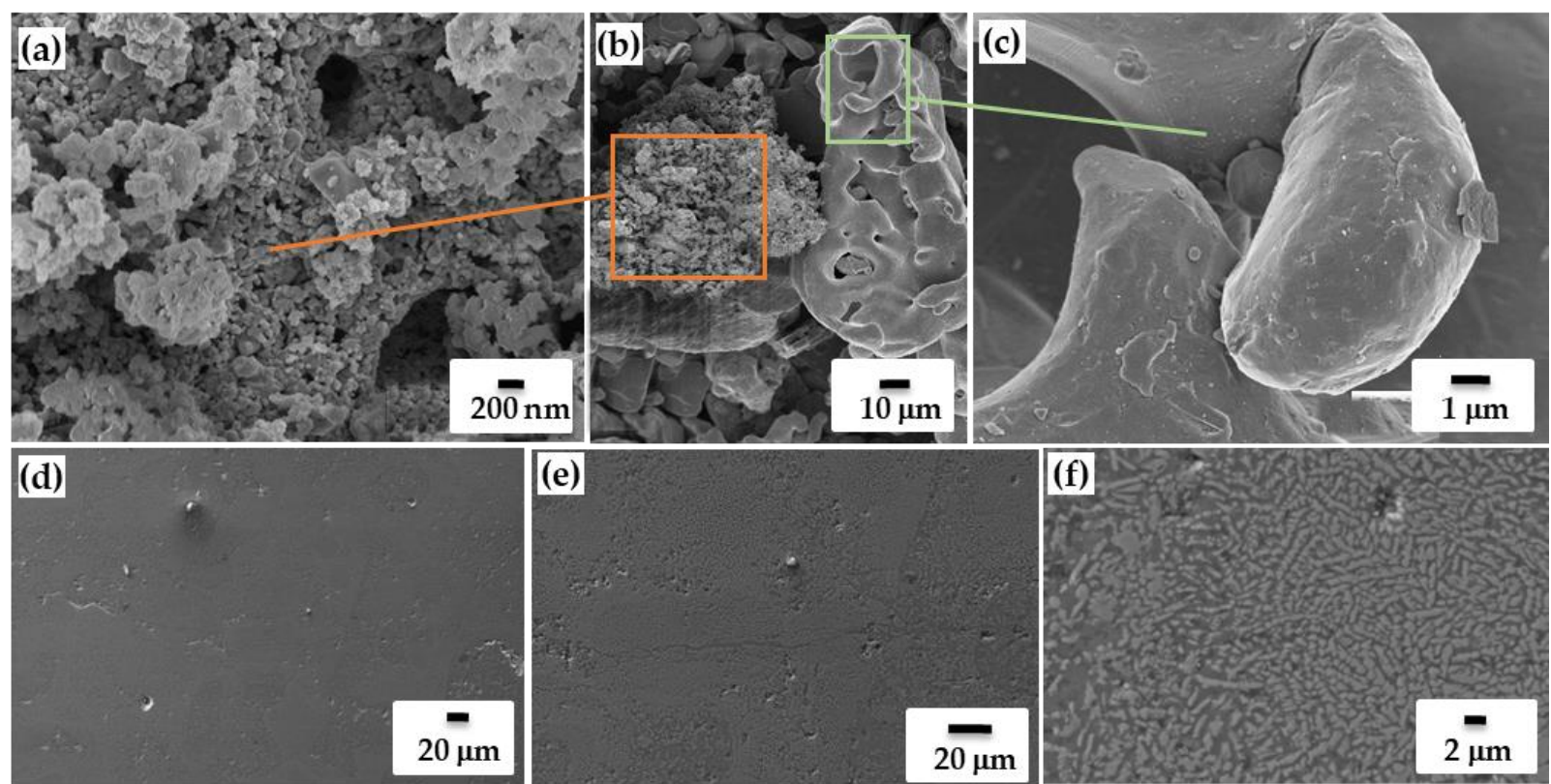

Figure 4. SEM image of $\mathrm{TiB}_{2}-\mathrm{Si}$ powder $(\mathbf{a}-\mathbf{c})$ and sintered fracture (d-f [39]).

The preparation $\mathrm{TiB}_{2} / \mathrm{Si}$ powder of specific morphology by combustion reaction may considerably promote the melting and solidification during sintering (Figure 4c). Indeed, in the SLM process, the $\mathrm{TiB}_{2}$ ceramic phase and silicon acquire mutual affinity without the formation of any chemical bonds, thereby contributing to the consolidation process without spurious phase formation. $\mathrm{TiB}_{2} / \mathrm{Si}$ coupons of geometric density from $\sim 87$ to $\sim 97 \%$ were additively manufactured by the SLM technique changing the laser current in the range 1400-2200 mA. A laser current of high intensity (I $>2200 \mathrm{~mA}$ ) was required for the fabrication of dense compacts of Vickers microhardness around $8 \mathrm{GPa}$. This is explained by the decrease of the viscosity of liquid silicon along with increase in laser current. As a result, $\mathrm{Si}$ inclusions are homogeneously distributed between the $\mathrm{TiB}_{2}$ particles preliminary stimulated by the "pomegranate-like" morphology of the feedstock. Fine-grained titanium diboride particulates render the role of nucleation seeds upon the cooling process and, due to the "pomegranate-like" microstructure, lend a hand to the more homogeneous solidification of silicon melt, thereby making it possible to prevent $\mathrm{Si}$ grain coarsening and decrease the risk of cracking at shrinkage. $\mathrm{TiB}_{2} / \mathrm{Si}$ composite microstructure is composed of micron-sized columnar grains $(2-10 \mu \mathrm{m}$ in length) and equiaxed submicron grains of ceramic phase dispersed in the Si matrix (Figure $4 \mathrm{~d}-\mathrm{f}$ ).

Aside from SLM, the SHS synthesized $\mathrm{TiB}_{2}+\mathrm{Si}$ and $\mathrm{TiB}_{2}+2 \mathrm{Si}$ composites were sintered in graphite crucibles at different temperatures (ranging from 1250 to $1350{ }^{\circ} \mathrm{C}$ ) [59]. Fully dense coupons of flat surface and fracture were successfully produced (Figure 5a). The highest hardness up to $11 \mathrm{GPa}$ of $\mathrm{TiB}_{2}$-Si composite sintered at $1350^{\circ} \mathrm{C}$ was achieved at lower Si content. The hardness of solid bulks produced by SLM of SHSed $\mathrm{TiB}_{2} / \mathrm{Si}$ composites of a relative density around $97 \%(7.6 \pm 1 \mathrm{GPa})$ was comparable with that of SPSed samples sintered at $1300{ }^{\circ} \mathrm{C}(7.2 \pm 0.5 \mathrm{GPa})$. The fracture toughness of the composite determined by different techniques ranges from 3.73 to $5.71 \mathrm{MPa} \cdot \mathrm{m}^{1 / 2}$ for the $\mathrm{TiB}_{2} / \mathrm{Si}$ samples consolidated at $1300{ }^{\circ} \mathrm{C}$. The average $\mathrm{FT}$ value is commensurate with $\mathrm{TiB}_{2}-\mathrm{SiC}-\mathrm{Si}$ composite with representative FT value of $3.5 \mathrm{MPa} \cdot \mathrm{m}^{1 / 2}$. The absence of notable chemical 
interaction between the constituents during the consolidation process was revealed by XRD examinations: after the sintering pattern comprised only the characteristic lines of $\mathrm{TiB}_{2}$ and silicon. Microstructural analysis showed that $\mathrm{TiB}_{2}$ particulates predominantly have rounded morphology inherited from the SHS process (Figure 5c). However, average size of fine grains (calculated for at least 100 grains) was around $0.5 \mu \mathrm{m}$ and for the coarse particles, $3 \mu \mathrm{m}$, suggesting ceramic particle coalescence during the sintering. The bulk samples with lower silicon amount ( 30 wt.\% vs. 44 wt.\%) demonstrated the lowest wear rate when subjected to erosion by silica sand in the whole temperature interval $\left(20-650{ }^{\circ} \mathrm{C}\right)$. The layer composed of silica was formed to protect further oxidation and decrease the wear at elevated temperatures. The oxide formation on the surfaces of samples was examined by Raman spectroscopy. The characteristic bands on Raman spectrum of $\mathrm{TiO}_{2}$ are on 145, 198, 399,516 , and $640 \mathrm{~cm}^{-1}$, and rutile on 240, 443, and $619 \mathrm{~cm}^{-1}$ and they are not observed in the samples up to $650{ }^{\circ} \mathrm{C}$. $\mathrm{SiO}_{2}$ formation started to be observed from $600{ }^{\circ} \mathrm{C}$ ( $\mathrm{Si}-\mathrm{O}-\mathrm{Si}$ network bending modes at $485 \mathrm{~cm}^{-1}$ ).
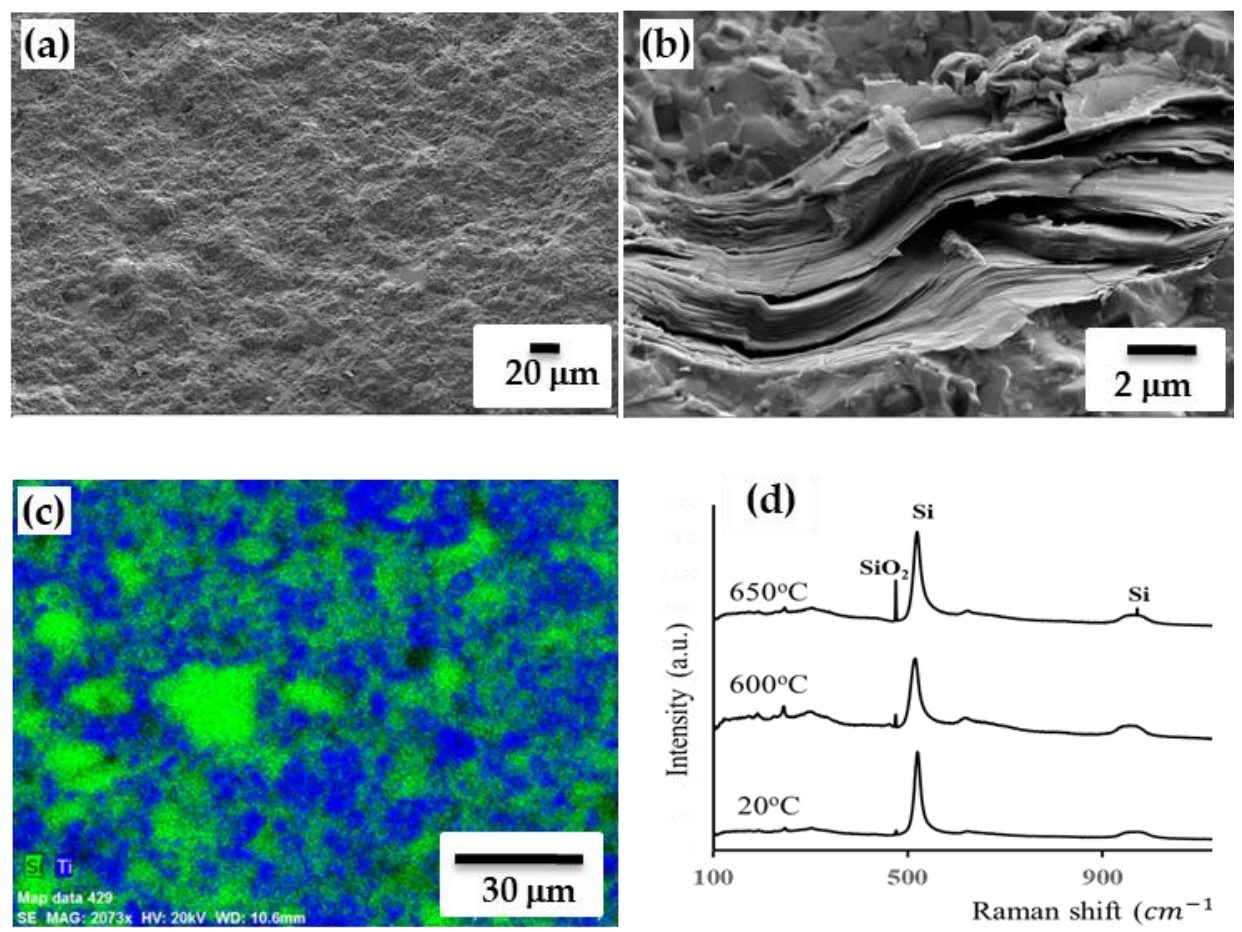

Figure 5. SEM images of $(\mathbf{a}, \mathbf{b})$ and EDS mapping (c) of $\mathrm{TiB}_{2}-\mathrm{Si}$ fracture surface after sintering $\left(\mathrm{T}=1280^{\circ} \mathrm{C}\right)$ and Raman spectrum after erosion by silica sand $(\mathrm{d})$.

Wrinkling/crumpling was observed during the sample fracturing (Figure 5b). The exfoliated layers of the composite embrace thickness down to hundreds of nanometers. The layered structure of $\mathrm{TiB}_{2}$ may assimilate to graphene-like boron sheets and propose their possible exfoliation into tiny 2D nanosheets, which was achieved here by mechanical exfoliation [60]. Refractory borides are usually utilized to fabricate materials as wear- and corrosion-resistant coatings, but layered $\mathrm{TiB}_{2}$ has a wide perspective as a catalyst of future for electrochemical energy applications.

\subsection{Titanium Diboride-Titanium System}

Titanium-based systems suffer from the homogeneous distribution of phases due to (i) high plasticity of titanium, which does not allow to effectively reduce particle size, (ii) explosibility of micron- and nano-sized titanium (self-ignition), thus the in situ dispersion or homogeneous distribution of particles through combustion reaction is of primary importance. Bearing these issues in mind, the SHS of commercial titanium $(<44 \mu \mathrm{m})$ and boron powders (1:0.85 mol ratio) was designed to produce TiB-Ti ceramic-based com- 
posite $[61,62]$. The excess amount of titanium played a role of diluent decreasing the combustion temperature up to $1700{ }^{\circ} \mathrm{C}$, which is $1000{ }^{\circ} \mathrm{C}$ lower compared to $\mathrm{T}_{\mathrm{c}}$ of the Ti-2B mixture. At combustion temperature, titanium was melted and boron was dissolved followed by further interaction up to the formation of mainly TiB along with some amount of $\mathrm{TiB}_{2}$ phase. An excess amount of $\mathrm{Ti}$ (theoretically calculated $0.15 \mathrm{~mol}$, but experimentally it was $>0.15 \mathrm{~mol}$ due to the presence of some amount of $\mathrm{TiB}_{2}$ ) acts as a matrix for the composite. Ti-TiB powder produced by SHS was characterized by median diameter (D50) of $10 \mu \mathrm{m}$ and represented conglomerates of fine-grained and coarse particulates of round-shaped and needle-shaped morphology along with spherical droplets of molten titanium found to be beneficial for further consolidation processes. Fully dense and thermodynamically stable TiB-Ti composites of high ceramic content $(88 \mathrm{wt} . \%$ according to Rietveld method) were produced at $1200{ }^{\circ} \mathrm{C}$ by spark plasma sintering of SHS-derived TiB-Ti ceramic-based powder. The composite exhibited homogeneous microstructure and a considerable hardness of 1550 HV30 (against of 1300 HV30 of specimen produced from commercial powders [62]) combined with a fair indentation FT value of $8.2 \mathrm{MPa} \cdot \mathrm{m}^{1 / 2}$. Comparative analysis with the fully dense composites by SPS at $1500{ }^{\circ} \mathrm{C}$ of the conventional milling and mixing commercially available powders of titanium and titanium diboride showed that higher sintering temperatures $\left(1200{ }^{\circ} \mathrm{C}\right.$ vs. $\left.1500{ }^{\circ} \mathrm{C}\right)$ were avoided due to utilization of SHS-produced powder along with refined and homogeneous microstructure of the composite material. The composites produced from SHSed "pomegranate-like" powders of so-called glued or pre-sintered state of grains from one hand and a bi-modal distribution of particles from another displayed improved sintering ability and toughening of the ceramic-based composite [40].

\subsection{Boron Carbide-Titanium-Nickel System}

Cold sintering of $\mathrm{B}_{4} \mathrm{C}-\mathrm{Ti}$-Ni powder blends was performed to in situ fabricate near-full density composites [63]. Combustion-assisted consolidation and reactive hot-pressing techniques were utilized. The processing/preheating temperature was $1100{ }^{\circ} \mathrm{C}$ in both approaches, which is significantly below the temperature typically used in current methods of processing/consolidation of ceramic matrix composites. During the combustionassisted consolidation, a complete conversion in the reactive mixture was achieved for the $\mathrm{B}_{4} \mathrm{C}-3 \mathrm{Ti}-1.5 \mathrm{Ni}$ blends. The moderate external pressure $(150 \mathrm{MPa})$ was beneficial to provide full densification of the final products that mainly contained $\mathrm{TiB}_{2}, \mathrm{TiC}$, and $\mathrm{Ni}$ with minor presence of unreacted boron carbide. The bright metallic phase practically consisted of nickel and surrounded fine $\mathrm{TiB}_{2}$ platelets and equiaxial TiC grains (Figure 6a). To mitigate the combustion conditions of the initial $\mathrm{B}_{4} \mathrm{C}-3 \mathrm{Ti}-1.5 \mathrm{Ni}$, a mixture $20 \mathrm{wt} . \%$ of $\mathrm{B}_{4} \mathrm{C}$ was added to the reagent blend as a diluting agent. Based on thermodynamic estimations, the combustion temperature for such diluted mixture is $2500^{\circ} \mathrm{C}$, whereas for the undiluted one, it reaches up to $\mathrm{T}_{\mathrm{ad}}=2950^{\circ} \mathrm{C}$. In contrast to the undiluted blend, the major phase in the diluted sample after the consolidation was $\mathrm{TiB}_{2}$ with some amount of $\mathrm{Ni}_{4} \mathrm{~B}_{3}$ and $\mathrm{B}_{4} \mathrm{C}$. $\mathrm{TiC}$ or other carbon-containing phases were not detected by XRD analysis. Therefore, from the SEM images, the presence of amorphous carbon is expected in the product of thermal explosion, Figure 6, displaying small spherical particles which are very similar to those precipitated from liquid carbon nodules. At excessive amounts of $\mathrm{B}_{4} \mathrm{C}$, boron binds with titanium and leads to the formation of the thermodynamically stable $\mathrm{TiB}_{2}$ according to $\mathrm{B}_{4} \mathrm{C}+2 \mathrm{Ti}=2 \mathrm{TiB}_{2}+\mathrm{C}$ reaction (free carbon is left). Obviously, during the cooling, some boron may recombine to free carbon to form boron carbide, but the formation of $\mathrm{Ni}_{4} \mathrm{~B}_{3}$ boride was also detected as a result of interaction of boron with molten nickel. The presence of this low melting $\mathrm{Ni}_{4} \mathrm{~B}_{3}$ component $\left(\mathrm{T}_{\mathrm{m}}=1030^{\circ} \mathrm{C}\right)$ in the end-product is not desirable especially for high temperature applications, hence $\mathrm{B}_{4} \mathrm{C}$ cannot be considered a relevant diluent for the system under consideration from the view of byproduct composition. 

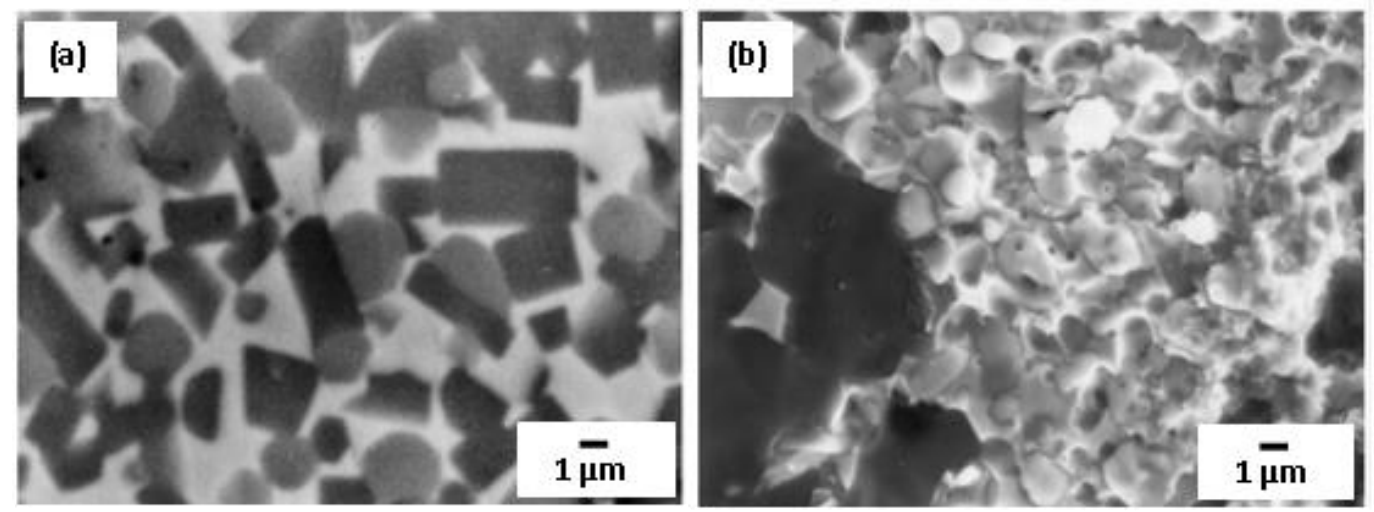

Figure 6. SEM micrograph of $\mathrm{TiB}_{2}-\mathrm{TiC}-\mathrm{Ni}$ composite synthesized by pressure-assisted combustion of dense $\mathrm{B}_{4} \mathrm{C}-3 \mathrm{Ti}-1.5 \mathrm{Ni}$ powder blend (derived from the center of the specimen) (a) and fracture surface of the product obtained from the $\mathrm{B}_{4} \mathrm{C}-3 \mathrm{Ti}-1.5 \mathrm{Ni}$ blend diluted by $20 \mathrm{wt}$. $\% \mathrm{~B}_{4} \mathrm{C}(\mathbf{b})$. Reprinted from Gotman et al., 1998 with copyright permission, Copyright 1998 Materials Science and Engineering: A [63].

\subsection{Silicon-Aluminum-Silicon Dioxide System}

b-SiAlON $(z=2-4)$ ceramics combine the properties of silicon nitride and aluminum oxide and are ideal candidates for cutting tips, gas filters, etc. SHS showed a large potential to rapidly synthesize SiAlON, but with careful selection of charge composition, amount, and type of diluent. In $[64,65]$, single phase b-SiAlON powder was prepared by CS method from $\mathrm{Si}, \mathrm{Al}$, and $\mathrm{SiO}_{2}$ mixture in the presence of up to $50 \mathrm{wt} . \% \mathrm{~b}-\mathrm{SiAlON}$ commercial powders as a diluent in $1 \mathrm{MPa} \mathrm{N}_{2}$ pressure. Without the diluent, the combustion temperature is high enough $\left(2000{ }^{\circ} \mathrm{C}\right)$ and unreacted silicon is present in the product. At 50 wt.\% dilution, $\mathrm{T}_{\mathrm{C}}$ is $1860{ }^{\circ} \mathrm{C}$ and the product is pure b-SiAlON ceramic. It was further subjected to SPS at $1600{ }^{\circ} \mathrm{C}$ for 5 min under $30 \mathrm{MPa}$ pressure and compacts of 93.3 and $97.57 \%$ density, 14.8 and $17.9 \mathrm{GPa}$ hardness, and 4.4 and $4.8 \mathrm{MPa} \cdot \mathrm{m}^{1 / 2}$ fracture toughness were produced for $b-\operatorname{SiAlON~} z=2$ and $z=4$ phases, respectively.

SEM images showed that as-synthesized SiAlON particles had irregular shapes with average particle size of $3 \mu \mathrm{m}$, which was preserved after the sintering (Figure 7).
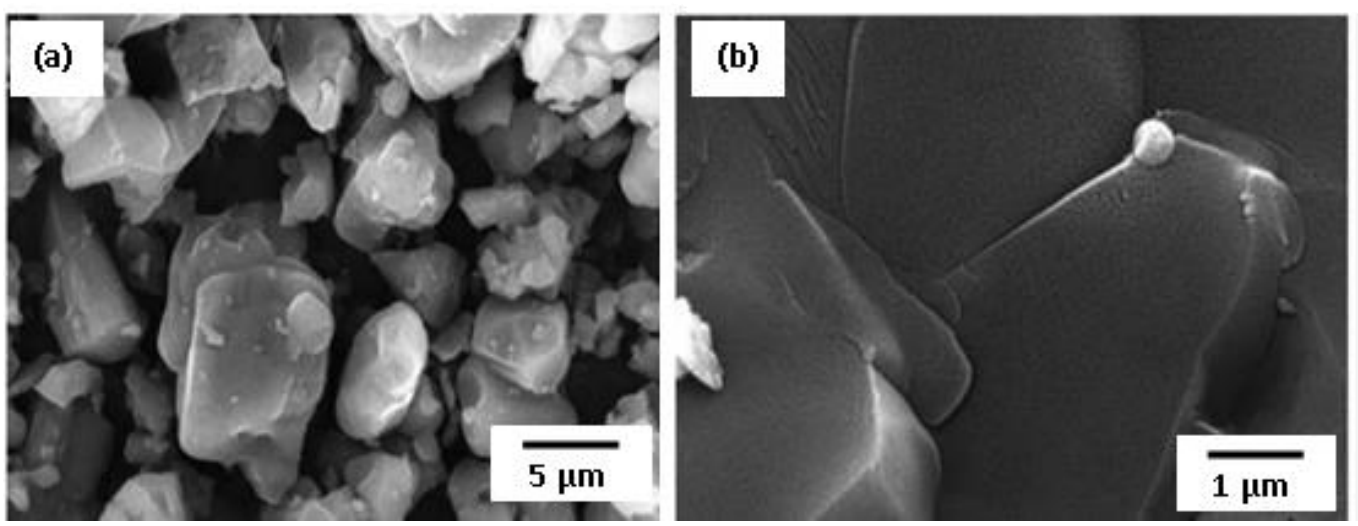

Figure 7. FE-SEM image of as-synthesized single-phase b-SiAlON (a) and fractured surface of bSiAlON sintered at $1600{ }^{\circ} \mathrm{C}$ (b). Reprinted with permission from Shahien et al. (2008), Copyright 2008, Journal of the Society of Materials Science, Japan [64].

\subsection{Zirconium-Nickel Oxide System}

The combustion synthesis was used for the preparation of Ni/YSZ (yttria-stabilized zirconia) ceramic-metal composites using the interaction between metallic $\mathrm{Zr}$ and $\mathrm{NiO}$ [66,67]. Thermite reactions between zirconium and nickel oxide $\left(2 \mathrm{NiO}+\mathrm{Zr} \rightarrow 2 \mathrm{Ni}+\mathrm{ZrO}_{2}\right)$ are 
highly exothermic, almost explosive in nature, and are characterized by adiabatic combustion temperature of $3110 \mathrm{~K}$, which exceeds the melting/boiling temperatures of the components. Hence, for the fabrication of dense solid coupons at moderate and controllable conditions, thermal dilution is extremely recommended. Utilizing a variety of precursors' mixtures with different amounts of diluting agents (monoclinic $\mathrm{ZrO}_{2}$, metallic nickel, cubic yttria), the combustion parameters, in particular temperature, can be carefully regulated to produce materials with different ratios of ceramic and metal components, as well as induce different morphologies of the constituting phases and controlled porosities. The main feature of the current pathway is the freedom from any external energy source during the interaction, and the availability to synthesize porous composites in one step, sinter it, control the porosity, and dope the ceramic component with yttria.

SEM observations of fracture surfaces (Figure 8) show the microstructures of composites derived by combustion reactions at (a) $\mathrm{T}_{\mathrm{ad}}=2950 \mathrm{~K}$ and (b) $\mathrm{T}_{\mathrm{ad}}=1730 \mathrm{~K}$. It is apparent that the ceramic matrix evolves spherical metallic particles. The strong relationship between particle size and $\mathrm{T}_{\mathrm{ad}}$ was demonstrated in addition to considerable modification of the ceramic matrix according to $T_{\text {ad }}$. In particular, the samples without diluent and high values of $T_{a d}$ showed extensive sintering and high degree of interconnectivity within ceramic and metal. These observations indicate the possibility of the partial melting of the ceramic phase at high $\mathrm{T}_{\mathrm{ad}}$ values.
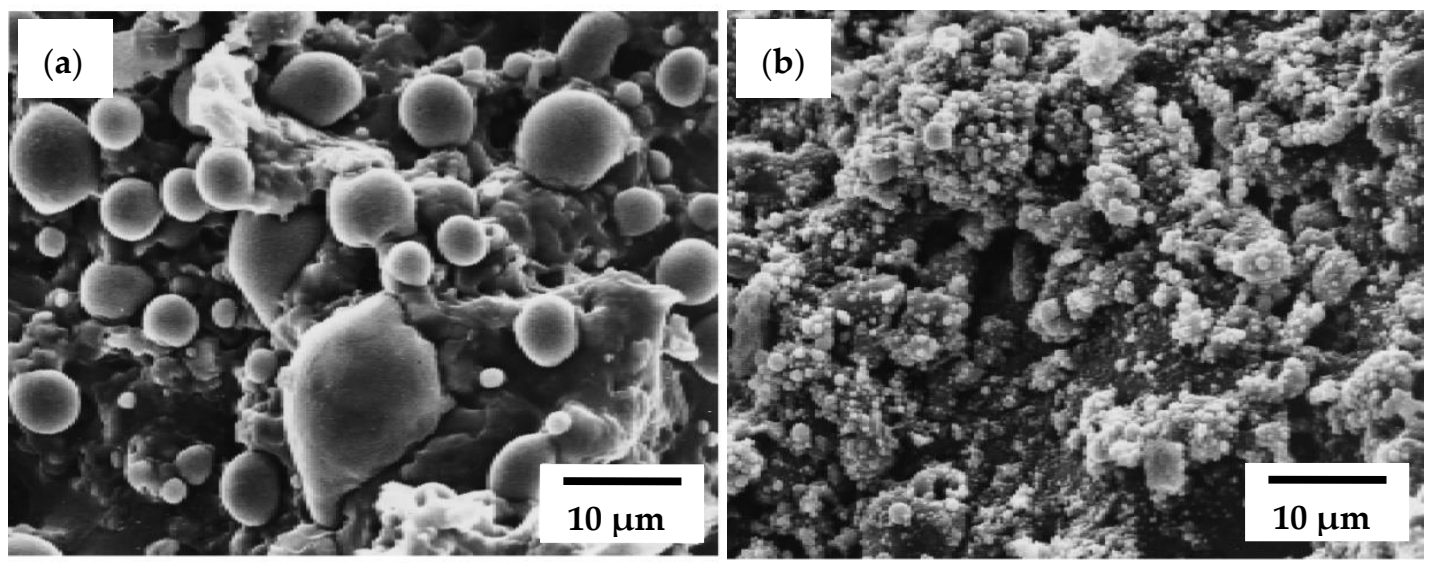

Figure 8. SEM examinations of fractures of cermets derived by combustion reactions at (a) $\mathrm{T}_{\mathrm{ad}}=2950 \mathrm{~K}$ and (b) $\mathrm{T}_{\mathrm{ad}}=1730 \mathrm{~K}$. Reprinted with permission from Anselmi-Tamburini et al. (1998), Copyright 1998 Journal of the American Ceramic Society [67].

\subsection{Molybdenium Trioxide-Silica-Aluminum System}

The preparation of dense mullite- $\mathrm{MoSi}_{2}$ composite material ( $<3$ vol.\% porosity) by pressure-assisted combustion synthesis from a reactive blend of composition $\mathrm{MoO}_{3}, \mathrm{SiO}_{2}$, and $\mathrm{Al}$ is detailed in [68]. Thermodynamic analyses predicts the probability of the development of the desired product in molten state with an adiabatic temperature of $2340 \mathrm{~K}$. Dilution of the reactive mixture with the combustion product (25 vol.\%) allowed to decrease the combustion temperature and stipulate homogeneous dispersion between the obtained phases.

The microstructural homogeneity of mullite-MoSi 2 composite is regarded to be the one of essential parameters with direct contribution to its physico-mechanical characteristics. Figure 9a displays the results of SEM examinations of the product without diluent. According to the results, authors showed almost complete separation between various phases, but big ceramic balls were developed in the central area of the specimen and small particles were found to be embedded into the mullite matrix. The observation was explained by the extremely high combustion temperature of the reaction $\left(T_{a d}=2340 \mathrm{~K}\right)$ exceeding the melting temperature of components $\left(\mathrm{T}_{\mathrm{m}}\left(\mathrm{MoSi}_{2}\right)=2303 \mathrm{~K}, \mathrm{~T}_{\mathrm{mMullite}}=2123 \mathrm{~K}\right)$. As a result, intensive agglomeration of the molten $\mathrm{MoSi}_{2}$ phase was observed during the consolida- 
tion process. All the physico-mechanical properties of the mullite-MoSi 2 composite were deteriorated by the inhomogeneous microstructure.
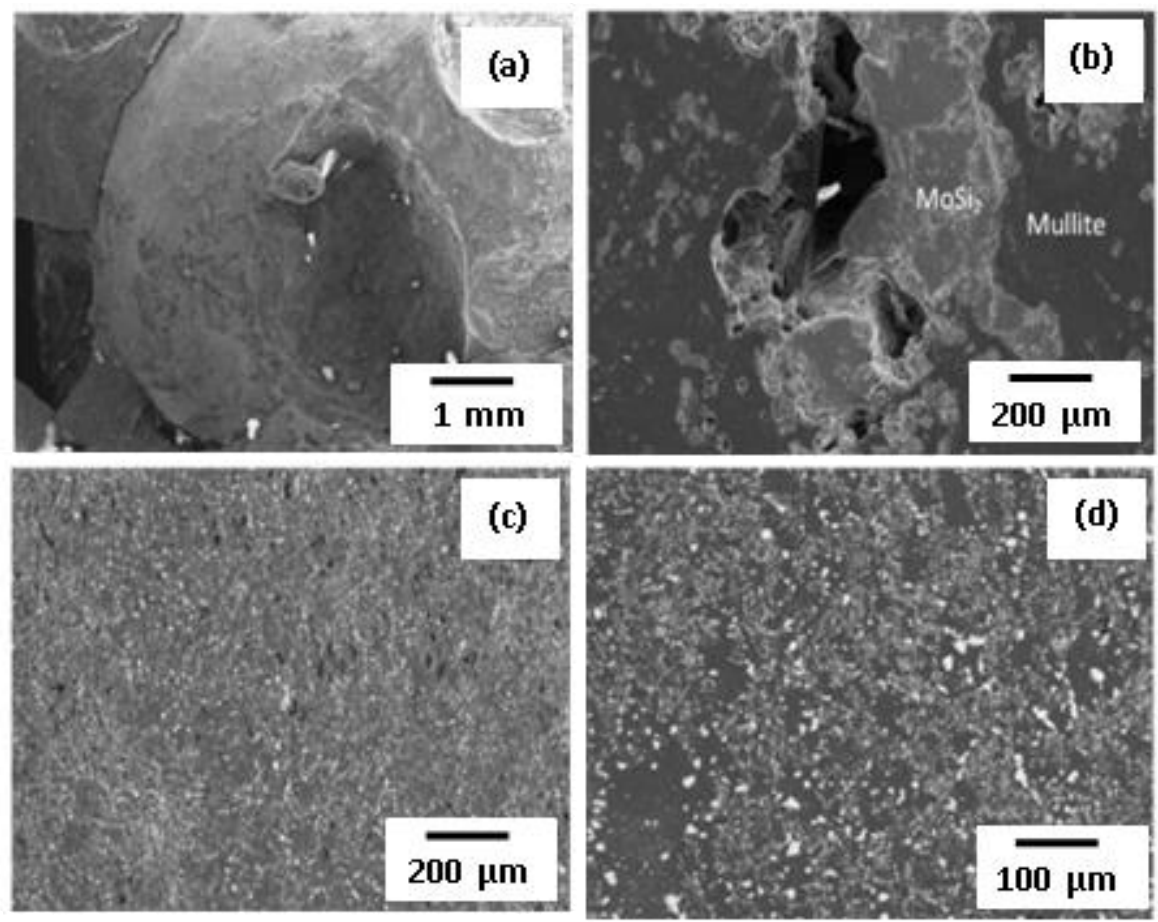

Figure 9. SEM micrographs of mullite-MoSi 2 composite: (a) without dilution; (b) diluted by 20 vol.\%; (c) diluted by $25 \mathrm{vol} \%$ and pressed at $82 \mathrm{MPa}$; (d) pressed at $234 \mathrm{MPa}$. Reprinted with permission from Zaki et al. (2014). Copyright 2014 International Journal of Refractory Metals and Hard Materials [68].

This vigorous reaction was inhibited by the addition of diluent for inhibiting the agglomeration of the molten silicide during consolidation. The diluent represented the combustion product of the same mixture. First, the product of undiluted reaction was ground, pulverized, and sieved $(20 \mu \mathrm{m})$. As it was proposed, the addition of diluting agent did not compromise the phase composition of the target product, but strongly influenced the microstructure. When comparing SEM micrographs (Figure 9) of the samples produced with different diluent amounts (20 or 25 vol.\%) with that of the composite without dilution, it is obvious that the particle size of silicide decreases from several $\mathrm{mm}$ up to few microns together with remarkable enhancement in the microstructural homogeneity among different phases. In the samples with 20 vol.\% of diluting agent (Figure 9b), regardless of the presence of big agglomerates of $\mathrm{MoSi}_{2}$ in the composite, their portion and size were significantly reduced compared to non-diluted systems (Figure 9a). Furthermore, the agglomerated phase completely disappeared by adding 25 vol.\% of diluent (Figure 9c). The aforementioned observations are attributed to the fluent decrease in the combustion temperature and reduction of the fraction of molten phases (mullite and $\mathrm{MoSi}_{2}$ ) at increasing the amount of diluting agent. The sample having a 25 vol.\% diluent amount has higher porosity at $82 \mathrm{MPa}$ pressing load but the highest degree of homogeneity among constituents. Thus, the pressing load of the composite was increased to reduce the sample porosity (the latter falls to 2.09 vol. $\%$ at $234 \mathrm{MPa}$ ).

\subsection{Boric Acid-Titania-Magnesium System}

Titanium diboride powder was produced by combustion synthesis of stoichiometric amounts of titania, boric acid, and magnesium. Up to $20 \mathrm{wt}$ \% of sodium chloride was introduced to the reactive mixture as a diluting agent $[69,70]$. As a result, a SHS product of particle size with less than $100 \mathrm{~nm}$ in size was received. The product demonstrated enhanced sinterability at lower temperatures and improved densification behavior. In 
particular, $97 \%$ relative density was achieved at $2223 \mathrm{~K}$ in contrast to the identically sintered samples from the commercially available powder ( $<86 \%$ at $2223 \mathrm{~K})$.

According to SEM observations of the fractures, different types of grains were originated: big platelets and small grains queued up in the SHS-made samples (Figure 10a). The formation of big platelets during the sintering was further explained by the bimodal distribution of the synthesized powder. The high-defect concentration of SHS powders might also be responsible for the evolution of big platelets.

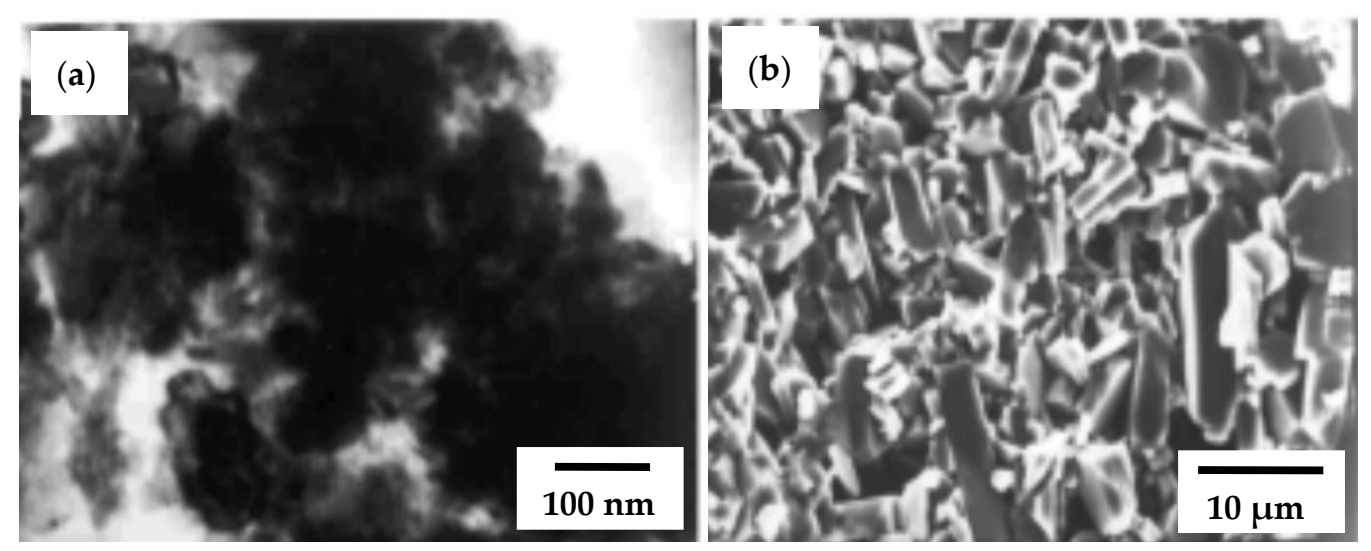

Figure 10. TEM image of $\mathrm{SHS} \mathrm{TiB}_{2}$ powder (a) and SEM fracture of $\mathrm{TiB}_{2}$ pellet sintered at $2123 \mathrm{~K}$ (b). Reprinted with permissiion from Khanra et al. (2005), Copyright 2005 Journal of the American Ceramic Society [69].

\subsection{Titanium-Boron-Copper System}

$\mathrm{TiB}_{2}$-based cermets with different copper content (the concentration of $\mathrm{TiB}_{2}$ varied from 45 to 90 vol.\%) are prepared from Ti, submicron boron, and copper powders by SHS and simultaneously densified by a technique called pseudo-isostatic pressing, when the heat released at the exothermic SHS interaction is utilized for the sintering [71]. The research aimed to quantitatively examine the influence of $\mathrm{TiB}_{2}$ as a strengthening phase in $\mathrm{Cu}$ matrix and characterize $\mathrm{TiB}_{2}-\mathrm{Cu}$ cermets containing from 45 to 90 vol. $\% \mathrm{TiB}_{2}$. Based on thermodynamic calculations, the adiabatic combustion temperature for the pure $\mathrm{TiB}_{2}$ formation makes $3190 \mathrm{~K}(0 \%$ of dilution). The adiabatic temperature decreases with the addition of copper. The adiabatic temperatures were $2843 \mathrm{~K}, 2652 \mathrm{~K}$, or $2284 \mathrm{~K}$ for the 70 , 60 , and 50 vol. $\% \mathrm{TiB}_{2}$-containing system, respectively. Therefore, a composite of small-sized particles was expected by the addition of copper, as the combustion synthesis of copper diluted $\mathrm{TiB}_{2}$ cermet is characterized by a lower exothermicity, hence a limited grain growth is feasible during the cooling process [72].

With the increasing copper content in the initial mixture, the average grain size significantly decreases. Coarse grains of several microns in size were found in the microstructure of up to 10-20 vol.\% Cu-containing mixtures, whereas ultrafine particles of average grain less than $0.6 \mu \mathrm{m}$ in size were observed in the composites when $\mathrm{TiB}_{2}$ reinforcing phase content decreased to 40-50 vol.\%. Moreover, the particle size distribution was also influenced by copper content (Figure 11). Monomodal distribution was certified for 5 vol.\% of $\mathrm{Cu}$ matrix composites, where small size $\mathrm{TiB}_{2}$ grains were predominating.

The phenomenon of intensive grain growth in the $\mathrm{TiB}_{2}$-based composites of high ceramic content is conditioned by the fact that the amount of ceramic phase drastically changes the maximum temperature in the reactive compact. At high concentration of $\mathrm{TiB}_{2}$ along with a small amount of $\mathrm{Cu}$ diluent, the maximum temperature increases ensuring dissolution of small-sized high energy grains and their precipitation on the bigger particles. To reduce the free energy of the system, larger precipitates are growing. 

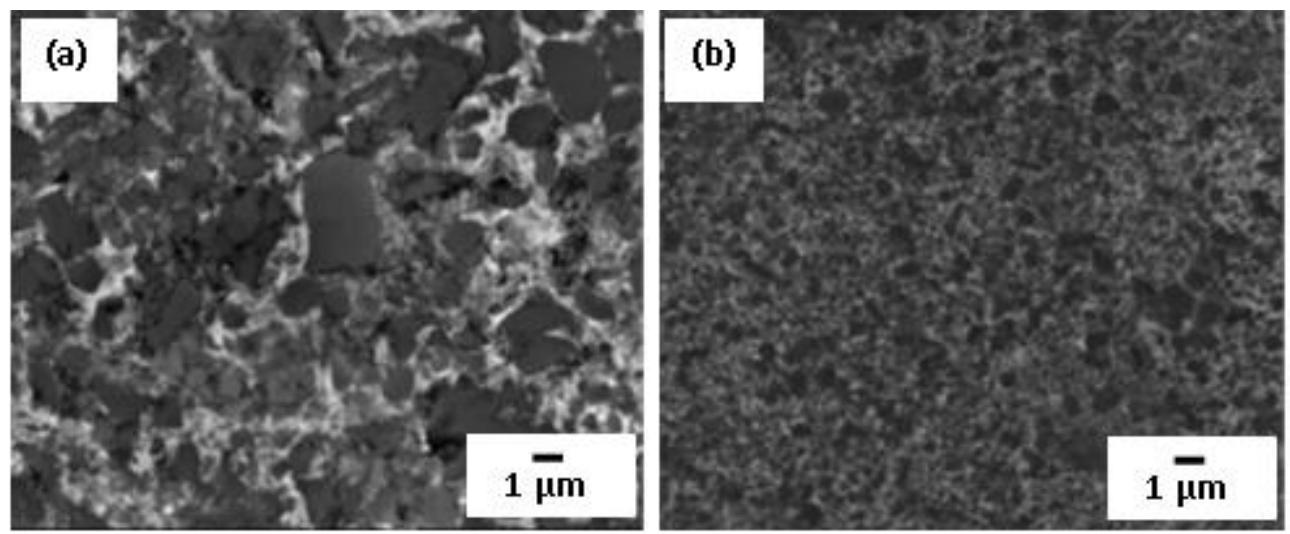

Figure 11. SEM microstructure for $\mathrm{TiB}_{2}-\mathrm{Cu}$ composites: (a) 70 vol. $\% \mathrm{TiB}_{2}$, and (b) 45 vol. $\% \mathrm{TiB}_{2}$. Reprinted with permission from Ziemnicka-Sylwester et al. (2014), Copyright 2014 Materials \& Design [72].

The hardness of 6-8 GPa measured for the specimens with ceramic phase concentration ranging from 45 to $75 \mathrm{vol} . \%$ is conditioned by high content of plastic copper matrix. The composites with predominant composition of $\mathrm{TiB}_{2}$ exhibit improved hardness, in particular, hardness value of 16-18 GPa was achieved for the composites with $85-90$ vol.\% of $\mathrm{TiB}_{2}$. Thus, the effect of copper diluent was demonstrated in terms of microstructure and hardness values. Increasing the binder content caused reduction in $\mathrm{TiB}_{2}$ grain size; however, the hardness substantially decreased when the concentration of $\mathrm{Cu}$ exceeded 15 vol.\%.

\section{Summary}

The role of thermal dilution on the combustion and microstructure formation features of different refractory ceramics and ceramic composites and the influence of porosity and thermal dilution on the combustion parameters was comprehensively discussed elsewhere. Various combustion regimes induced by phase transformations and phase formation mechanisms were deduced vs. the amount of inert diluent. Thermal/inert dilution of the high-exothermic mixtures by one of the end-products has been widely reported in terms of direct contribution to the temperature-controlled self-sustaining process and wide potential for designing new systems with several advantageous properties (high degree of conversion, homogeneity, uniform morphology). In other words, the thermal dilution of the initial mixture allowed to tailor the thermal regime of the combustion reaction and the microstructural features of the combustion products. The high-exothermic mixtures tend to be mitigated by the presence of diluting agents via simultaneous decrease in the combustion parameters (combustion temperature and velocity), therewith contributing to the reaction pathway by various mechanisms and allowing to produce refractory ceramic composite powders of certain morphology. The possibilities of the dilution strategy as a tool to control combustion behavior for the fabrication of suitable feedstock for the successful sintering was discussed in the current review. The effectiveness of the dilution strategy to control the thermal regime of the SHS process for the preparation of applicable powder precursors for the subsequent successful sintering was elucidated. The violent character of SHS of some refractory ceramic composites was alleviated due to the thermal dilution approach, and significant enhancement in the homogeneity of different phases along with microstructure refinement was observed when the amount of diluent was increased. The dilution of $\mathrm{MoSi}_{2}$ refractory phase via silicon leads to improved strength and moderate hardness thanks to the specific texture of SHS-derived powder preserved during SLM processing. The dilution of $\mathrm{MoSi}_{2}$ by $30 \mathrm{wt} . \% \mathrm{AlSi10Mg}$ alloy mixture tends to generate fine columnar dendritic structures smoothly intertwined with elongated grains with a fine divorced cellular structure under laser treatment. The combustion synthesis in the silicon diluted $\mathrm{TiB}_{2}-\mathrm{Si}$ system leads to the formation of specific "pomegranate-like" particles which represents an assembly of fine ceramic particulates "gluing" each other by silicon highly relevant for the 
melting/solidification during both the SLM and the SPS processes. The dilution by titanium of the $\mathrm{TiB}_{2}$-Ti system allowed to avoid higher sintering temperatures due to utilization of SHS-produced powder along with refined and homogeneous microstructure of the fully dense composites. By the presence of combustion product as a diluent in the SiAlON preparation, the complete interaction of precursors was achieved; as a result, irregular shapes with average particle size of $3 \mu \mathrm{m}$ were formed, which was preserved after the sintering. Yttria-stabilized zirconia cermets of certain porosity were produced by careful control of explosive $\mathrm{NiO}+\mathrm{Zr}$ reaction, where the dimensions of spherical metal particles embedded in the ceramic matrix are strongly dependent on $\mathrm{T}_{\mathrm{ad}}$. Regular decrease in the particle size of refractory ceramic-based composites (from several $\mathrm{mm}$ to few $\mu \mathrm{m}$, and from $\mu \mathrm{m}$ to $\mathrm{nm}$ depending on the precursors' particle size) with a considerable enhancement in the homogeneity among the phases was revealed when the amount of diluent increased. The SHS powders derived from diluted mixtures demonstrated excellent sinterability at lower temperatures and enhanced properties; for example, a higher densification of $97 \%$ densification was achieved at $2223 \mathrm{~K}$ for salt-diluted SHS-made $\mathrm{TiB}_{2}$, whereas the commercial powder sintered at the identical conditions could only be densified to $<86 \%$ at $2223 \mathrm{~K}$. Dilution of $\mathrm{TiB}_{2}$ by copper binder caused reduction of $\mathrm{TiB}_{2}$ grain size, without significant decline in hardness up to $15 \mathrm{vol} \% \mathrm{Cu}$. According to the type and quantity of diluents used, different mechanisms were provoked and, as a result, different morphologies were obtained in the products. However, in all cases the dilution allowed to control the thermal regime of the violent combustion process for the preparation of applicable powder precursors for the subsequent successful sintering. The expansion and design of novel systems by diluting the exothermic mixture without the contamination of product and deterioration of physico-mechanical characteristics is foreseen for future works.

Author Contributions: Conceptualization, S.A.; methodology, S.A., S.K. and I.H.; investigation, S.A.; resources, S.A. and I.H.; data curation, S.A., S.K. and I.H.; writing-original draft preparation, S.A.; writing-review and editing, S.K. and I.H.; visualization, S.A.; funding acquisition, S.A. and I.H. All authors have read and agreed to the published version of the manuscript.

Funding: This work was supported by Estonian Research Council, Estonia, under Grants PSG220 (S. Aydinyan) and PRG643 (I. Hussainova).

Data Availability Statement: The authors confirm that the data supporting the findings of this study are available within the article.

Conflicts of Interest: The authors declare no conflict of interest.

\section{References}

1. Mukasyan, A. Combustion synthesis of nitrides: Mechanistic studies. Proc. Combust. Inst. 2005, 30, 2529-2535. [CrossRef]

2. Mossino, P. Some aspects in self-propagating high-temperature synthesis. Ceram. Int. 2004, 30, 311-332. [CrossRef]

3. Merzhanov, A.G.; Sharivker, S.Y. Self-propagating high-temperature synthesis of carbides, nitrides, and borides. In Materials Science of Carbides, Nitrides and Borides; Springer: Dordrecht, The Netherlands, 1999; Volume 68, pp. $205-222$.

4. Borovinskaya, I.P.; Loryan, V.E.; Zakorzhevsky, V.V. Combustion synthesis of nitrides for development of ceramic materials of new generation. In Nitride Ceramics: Combustion Synthesis, Properties and Applications; Wiley-VCH: Weinheim, Germany, 2014; Chapter 1; pp. 1-47.

5. Vorotilo, S.; Potanin, A.Y.; Pogozhev, Y.S.; Levashov, E.A.; Kochetov, N.A.; Kovalev, D.Y. Self-propagating high-temperature synthesis of advanced ceramics MoSi2-HfB2-MoB. Ceram. Int. 2019, 45, 96-107. [CrossRef]

6. Zhang, Y.; Yao, D.; Zuo, K.; Xia, Y.; Yin, J.; Liang, H.; Zeng, Y.P. Effects of $\mathrm{N}_{2}$ pressure and Si particle size on mechanical properties of porous $\mathrm{Si}_{3} \mathrm{~N}_{4}$ ceramics prepared via SHS. J. Eur. Ceram. Soc. 2020, 40, 4454-4461. [CrossRef]

7. Chizhikov, A.P.; Konstantinov, A.S. Production of Ceramic Plates Based on $\mathrm{Al}_{2} \mathrm{O}_{3}-\mathrm{TiB}_{2}$ by Free SHS Compression. Refract. Ind. Ceram. 2021, 62, 94-97. [CrossRef]

8. Moore, J.J.; Feng, H.J. Combustion synthesis of advanced materials: Part I. Reaction parameters. Prog. Mater. Sci. 1995, 39, 243-273. [CrossRef]

9. Aydinyan, S.; Kharatyan, S.; Hussainova, I. SHS-Derived Powders by Reactions' Coupling as Primary Products for Subsequent Consolidation. Materials 2021, 14, 5117. [CrossRef]

10. Yeh, C.L.; Chuang, H.C.; Liu, E.W.; Chang, Y.C. Effects of dilution and preheating on SHS of vanadium nitride. Ceram. Int. 2005, 31, 95-104. [CrossRef] 
11. Yeh, C.L.; Chen, Y.D. Combustion synthesis of vanadium carbonitride from VC powder compacts under nitrogen pressure. Ceram. Int. 2007, 33, 365-371. [CrossRef]

12. Khachatryan, L.; Hobosyan, M.A.; Kharatyan, S.L.; Puszynski, J.A. Combustion Synthesis (SHS) of BN/AlN Ceramic Composite Powders. In Innovative Processing Synthesis Ceramics Glasses and Composites, Ceramic Transactions; John Wiley \& Sons: Indianapolis, IN, USA, 2004; Volume 166, pp. 3-10.

13. Sakurai, T.; Yamada, O.; Miyamoto, Y. Combustion synthesis of fine AlN powder and its reaction control. Mater. Sci. Eng. A 2006, 416, 40-44. [CrossRef]

14. Yeh, C.L.; Kuo, C.W.; Wu, F.S. Formation of $\mathrm{Ti}_{2} \mathrm{AlN}$ by Solid-Gas Combustion Synthesis with AlN- and TiN- Diluted Samples in Nitrogen. Int. J. Appl. Ceram. Technol. 2010, 7, 730-737. [CrossRef]

15. Cui, W.; Zhu, Y.; Ge, Y.; Kang, F.; Yuan, X.; Chen, K. Effects of nitrogen pressure and diluent content on the morphology of gel-cast-foam-assisted combustion synthesis of elongated $\beta$-Si3N4 particles. Ceram. Int. 2014, 40, 12553-12560. [CrossRef]

16. Khachatryan, G.L.; Arutyunyan, A.B.; Kharatyan, S.L. Activated combustion of a silicon-carbon mixture in nitrogen and SHS of $\mathrm{Si}_{3} \mathrm{~N}_{4}$-SiC composite ceramic powders and silicon carbide. Combust. Explos. Shock. Waves 2006, 42, 543-548. [CrossRef]

17. Manukyan, K.V.; Aydinyan, S.V.; Kirakosyan, K.G.; Kharatyan, S.L.; Blugan, G.; Müller, U.; Kuebler, J. Molten salt-assisted combustion synthesis and characterization of $\mathrm{MoSi}_{2}$ and $\mathrm{MoSi}_{2}-\mathrm{Si}_{3} \mathrm{~N}_{4}$ composite powders. Chem. Eng. J. 2008, 143, 331-336. [CrossRef]

18. Yeh, C.L.; Teng, G.S. Use of $\mathrm{BN}$ as a reactant in combustion synthesis of $\mathrm{TiN}^{-\mathrm{TiB}_{2}}$ composites under nitrogen pressure. J. Alloys Compd. 2006, 417, 109-115. [CrossRef]

19. Choi, Y.; Rhee, S.W. Effect of precursors on the combustion synthesis of TiC- $\mathrm{Al}_{2} \mathrm{O}_{3}$ composite. J. Mater. Res. 1994, 9, 1761-1766. [CrossRef]

20. Zhang, X.J.; Zheng, Y.T.; Han, J.C. The Effect of Diluent on Combustion Synthesis of $\mathrm{Si}_{3} \mathrm{~N}_{4}-\mathrm{SiC}$-TiN Ceramics with Small Diameter. In Key Engineering Materials; Trans Tech Publications Ltd.: Stafa-Zurich, Switzerland, 2007; Volume 336, pp. $1084-1086$.

21. Lakshmikantha, M.; Sekhar, J.A. Analytical modeling of the propagation of a thermal reaction front in condensed systems. J. Am. Ceram. Soc. 1994, 77, 202-210. [CrossRef]

22. Martinez Pacheco, M.; Bouma, R.; Arias Cuevas, O.; Katgerman, L. Experimental Study and Modelling of Combustion Front Velocity in Ti-2B and Ti-C based Reactant Mixtures. In Advances in Science and Technology; Trans Tech Publications Ltd.: Stafa-Zurich, Switzerland, 2006; Volume 45, pp. 2656-2663.

23. Makino, A.; Araki, N.; Kuwabara, T. Flammability limits, dilution limits and effect of particle size on burning velocity in combustion synthesis of TiC. JSME Int. J. Ser. B Fluids Therm. Eng. 1994, 37, 576-582. [CrossRef]

24. Yeh, C.L.; Wang, H.J. A comparative study on combustion synthesis of Ta-B compounds. Ceram. Int. 2011, 37, 1569-1573. [CrossRef]

25. Prokof'ev, V.G.; Smolyakov, V.K. Unsteady combustion regimes of gasless systems with a low-melting inert component. Combust. Explos. Shock. Waves 2002, 38, 143-147. [CrossRef]

26. Yeh, C.L.; Chuang, H.C. Combustion characteristics of SHS process of titanium nitride with TiN dilution. Ceram. Int. 2004, 30, 705-714. [CrossRef]

27. Zakaryan, M.K.; Aydinyan, S.V.; Kharatyan, S.L. Preparation of fine-grained silicon from serpentine mineral by magnesiothermic reduction of silica in the presence of reaction products as diluents. Silicon 2017, 9, 841-846. [CrossRef]

28. Ryu, H.Y.; Nersisyan, H.H.; Lee, J.H. Preparation of zirconium-based ceramic and composite fine-grained powders. Int. J. Refract. Met. Hard Mater. 2012, 30, 133-138. [CrossRef]

29. Khanra, A.K.; Pathak, L.C.; Godkhindi, M.M. Double SHS of ZrB 2 powder. J. Mater. Processing Technol. 2008, 202, 386-390. [CrossRef]

30. Cordova, S.; Shafirovich, E. Toward a better conversion in magnesiothermic SHS of zirconium diboride. J. Mater. Sci. 2018, 53, 13600-13616. [CrossRef]

31. Han, C.; Babicheva, R.; Chua, J.D.Q.; Ramamurty, U.; Tor, S.B.; Sun, C.N.; Zhou, K. Microstructure and mechanical properties of $(\mathrm{TiB}+\mathrm{TiC}) / \mathrm{Ti}$ composites fabricated in situ via selective laser melting of Ti and $\mathrm{B}_{4} \mathrm{C}$ powders. Addit. Manuf. 2020, 36, 101466. [CrossRef]

32. Aramian, A.; Razavi, S.M.J.; Sadeghian, Z.; Berto, F. A review of additive manufacturing of cermets. Addit. Manuf. 2020, 33, 101130. [CrossRef]

33. Grigoriev, S.; Tarasova, T.; Gusarov, A.; Khmyrov, R.; Egorov, S. Possibilities of manufacturing products from cermet compositions using nanoscale powders by additive manufacturing methods. Materials 2019, 12, 3425. [CrossRef]

34. Tkachenko, S.; Cizek, J.; Mušálek, R.; Dvořák, K.; Spotz, Z.; Montufar, E.B.; Čelko, L. Metal matrix to ceramic matrix transition via feedstock processing of SPS titanium composites alloyed with high silicone content. J. Alloys Compd. 2018, 764, 776-788. [CrossRef]

35. Su, X.; Dong, J.; Chu, L.; Sun, H.; Grasso, S.; Hu, C. Synthesis, microstructure and properties of MoAlB ceramics prepared by in situ reactive spark plasma sintering. Ceram. Int. 2020, 46, 15214-15221. [CrossRef]

36. Buravlev, I.Y.; Shichalin, O.O.; Papynov, E.K.; Golub, A.V.; Gridasova, E.A.; Buravleva, A.A.; Sergienko, V.I. WC-5TiC-10Co hard metal alloy fabrication via mechanochemical and SPS techniques. Int. J. Refract. Met. Hard Mater. 2021, 94, 105385. [CrossRef] 
37. Lantcev, E.; Nokhrin, A.; Malekhonova, N.; Boldin, M.; Chuvil'deev, V.; Blagoveshchenskiy, Y.; Murashov, A. A Study of the Impact of Graphite on the Kinetics of SPS in Nano-and Submicron WC-10\% Co Powder Compositions. Ceramics 2021, 4, 331-363. [CrossRef]

38. Minasyan, T.; Liu, L.; Aydinyan, S.; Kollo, L.; Hussainova, I.; Rodríguez, M.A. Combustion synthesis of MoSi 2 based composite and selective laser sintering thereof. J. Eur. Ceram. Soc. 2018, 38, 3814-3821. [CrossRef]

39. Liu, L.; Aydinyan, S.; Minasyan, T.; Hussainova, I. SHS Produced TiB 2 -Si Powders for Selective Laser Melting of Ceramic-Based Composite. Appl. Sci. 2020, 10, 3283. [CrossRef]

40. Kumar, R.; Liu, L.; Antonov, M.; Ivanov, R.; Hussainova, I. Hot Sliding Wear of 88wt.\%TiB-Ti Composite from SHS Produced Powders. Materials 2021, 14, 1242. [CrossRef]

41. Yeh, C.L.; Chen, W.L. A combustion route to synthesize $\mathrm{Mo}_{5} \mathrm{SiB}_{2}-\mathrm{Al}_{2} \mathrm{O}_{3}$ composites. Vacuum 2019, 163, 288-291. [CrossRef]

42. Yeh, C.L.; Chen, Y.C. Formation of $\mathrm{Mo}_{5} \mathrm{Si}_{3} / \mathrm{Mo}_{3} \mathrm{Si}-\mathrm{MgAl}_{2} \mathrm{O}_{4}$ composites via self-propagating high-temperature synthesis. Molecules 2020, 25, 83. [CrossRef] [PubMed]

43. Shen, J.; Zou, B.; Dong, S.; Cai, X.; Cao, X. Fabrication and characterization of $\mathrm{TiB}_{2}$-TiC-Co wear-resistant coatings on AZ91D magnesium alloy. Surf. Coat. Technol. 2019, 364, 358-368. [CrossRef]

44. Merzhanov, A.G.; Rogachev, A.S. Structural macrokinetics of SHS processes. Pure Appl. Chem. 1992, 64, 941-953. [CrossRef]

45. Won, C.W.; Nersisyan, H.H.; Won, H.I.; Lee, J.H. Refractory metal nanopowders: Synthesis and characterization. Curr. Opin. Solid State Mater. Sci. 2010, 14, 53-68. [CrossRef]

46. Nersisyan, H.H.; Lee, J.H.; Ding, J.R.; Kim, K.S.; Manukyan, K.V.; Mukasyan, A.S. Combustion synthesis of zero-, one-, two-and three-dimensional nanostructures: Current trends and future perspectives. Prog. Energy Combust. Sci. 2017, 63, 79-118. [CrossRef]

47. Ahmed, Y.M.Z.; Zaki, Z.I.; Bordia, R.K.; Besisa, D.H.A.; Amin, A.M.M. Simultaneous synthesis and sintering of TiC/ $\mathrm{Al}_{2} \mathrm{O}_{3}$ composite via self-propagating synthesis with direct consolidation technique. Ceram. Int. 2016, 42, 16589-16597. [CrossRef]

48. Yang, P.; Xiao, G.; Ding, D.; Ren, Y.; Zhang, Z.; Yang, S.; Zhang, W. Mechanism of Self-Propagating High-Temperature Synthesis of $\mathrm{AlB}_{2}-\mathrm{Al}_{2} \mathrm{O}_{3}$ Composite Powders. Refract. Ind. Ceram. 2019, 60, 46-54. [CrossRef]

49. Zakorzhevskii, V.V.; Borovinskaya, I.P. SHS of $\alpha-\mathrm{Si}_{3} \mathrm{~N}_{4}$ from fine Si powders in the presence of blowing agents. Int. J. SelfPropagating High-Temp. Synth. 2011, 20, 156-160. [CrossRef]

50. Song, M.S.; Zhang, M.X.; Zhang, S.G.; Huang, B.; Li, J.G. In situ fabrication of TiC particulates locally reinforced aluminum matrix composites by selfpropagating reaction during casting. Mater. Sci. Eng. A 2008, 473, 166-171. [CrossRef]

51. Farje, J.A.V.; Matsunoshita, H.; Kishida, K.; Inui, H. Microstructure and mechanical properties of a $\mathrm{MoSi}_{2}-\mathrm{Mo}_{5} \mathrm{Si}_{3}$ eutectic composite processed by laser surface melting. Mater. Charact. 2019, 148, 162-170. [CrossRef]

52. Hagihara, K.; Nakano, T.; Suzuki, M.; Ishimoto, T.; Sun, S.H. Successful additive manufacturing of MoSi ${ }_{2}$ including crystallographic texture and shape control. J. Alloys Compd. 2017, 696, 67-72. [CrossRef]

53. Minasyan, T.; Liu, L.; Holovenko, Y.; Aydinyan, S.; Hussainova, I. Additively manufactured mesostructured $\mathrm{MoSi}_{2}-\mathrm{Si}_{3} \mathrm{~N}_{4}$ ceramic lattice. Ceram. Int. 2019, 45, 9926-9933. [CrossRef]

54. Liu, Y.; Shao, G.; Tsakiropoulos, P. Thermodynamic reassessment of the Mo-Si and Al-Mo-Si systems. Intermetallics 2000, 8, 953-962. [CrossRef]

55. Liu, L.; Minasyan, T.; Aydinyan, S.; Aghayan, M.; Hussainova, I. Self-Functionalizing Fibrous Networks of $\mathrm{Si}_{3} \mathrm{~N}_{4}$ with Complex Geometry and Manufacturing Thereof. European Union Patent EP17174463.4, 5 June 2017.

56. Minasyan, T.; Aydinyan, S.; Toyserkani, E.; Hussainova, I. In Situ Mo(Si,Al) ${ }_{2}$-based Composite through Selective Laser Melting of a MoSi 2 -30wt.\%AlSi10Mg Mixture. Materials 2020, 13, 3720. [CrossRef] [PubMed]

57. Minasyan, T.; Aydinyan, S.; Toyserkani, E.; Hussainova, I. Parametric Study on In Situ Laser Powder Bed Fusion of Mo(Si $\left.i_{1-x}, \mathrm{Al}_{\mathrm{x}}\right)_{2}$. Materials 2020, 13, 4849. [CrossRef] [PubMed]

58. Yang, Y.; Chang, Y.A.; Tan, L. Thermodynamic modeling and experimental investigation of the Ti-rich corner of the Ti-Si-B system. Intermetallics 2005, 13, 1110-1115. [CrossRef]

59. Liu, L.; Aydinyan, S.; Minasyan, T.; Baronins, J.; Antonov, M.; Kharatyan, S.; Hussainova, I. Spark Plasma Sintering of Combustion Synthesized $\mathrm{TiB}_{2}$-Si Composite. Ceram. Mod. Technol. 2018, 10, 3283. [CrossRef]

60. Lim, C.S.; Sofer, Z.; Mazánek, V.; Pumera, M. Layered titanium diboride: Towards exfoliation and electrochemical applications. Nanoscale 2015, 7, 12527-12534. [CrossRef]

61. Ma, X.; Li, C.; Du, Z.; Zhang, W. Thermodynamic assessment of the Ti-B system. J. Alloys Compd. 2004, 370, 149-158. [CrossRef]

62. Kumar, R.; Antonov, M.; Liu, L.; Hussainova, I. Sliding wear performance of in-situ spark plasma sintered Ti-TiBw composite at temperatures up to $900^{\circ} \mathrm{C}$. Wear 2021, 476, 203663. [CrossRef]

63. Gotman, I.; Travitzky, N.A.; Gutmanas, E.Y. Dense in situ $\mathrm{TiB}_{2} / \mathrm{TiN}$ and $\mathrm{TiB}_{2} / \mathrm{TiC}$ ceramic matrix composites: Reactive synthesis and properties. Mater. Sci. Eng. A 1998, 244, 127-137. [CrossRef]

64. Shahien, M.; Radwan, M.; Kirihara, S.; Miyamoto, Y.; Sakurai, T. Combustion synthesis and sintering of $\beta$-sialon ceramics $(\mathrm{z}=2)$. J. Soc. Mater. Sci. 2008, 57, 1248-1252. [CrossRef]

65. Shahien, M.; Radwan, M.; Kirihara, S.; Miyamoto, Y.; Sakurai, T. Combustion synthesis of single-phase $\beta$-sialons (z = 2-4). J. Eur. Ceram. Soc. 2010, 30, 1925-1930. [CrossRef]

66. Anselmi-Tamburini, U.; Chiodelli, G.; Arimondi, M.; Maglia, F.; Spinolo, G.; Munir, Z.A. Electrical properties of Ni/YSZ cermets obtained through combustion synthesis. Solid State Ion. 1998, 110, 35-43. [CrossRef] 
67. Anselmi-Tamburini, U.; Arimondi, M.; Maglia, F.; Spinolo, G.; Munir, Z.A. Nickel/Yttria-Stabilized Zirconia Cermets from Combustion Synthesis: Effect of Process Parameters on Product Microstructure. J. Am. Ceram. Soc. 1998, 81, 1765-1772. [CrossRef]

68. Zaki, Z.I.; Mostafa, N.Y.; Ahmed, Y.M.Z. Synthesis of dense mullite/ $\mathrm{MoSi}_{2}$ composite for high temperature applications. Int. J. Refract. Met. Hard Mater. 2014, 45, 23-30. [CrossRef]

69. Khanra, A.K.; Godkhindi, M.M.; Pathak, L.C. Comparative Studies on Sintering Behavior of Self-Propagating High-Temperature Synthesized Ultra-Fine Titanium Diboride Powder. J. Am. Ceram. Soc. 2005, 88, 1619-1621. [CrossRef]

70. Khanra, A.K.; Pathak, L.C.; Mishra, S.K.; Godkhindi, M.M. Effect of $\mathrm{NaCl}$ on the synthesis of $\mathrm{TiB}_{2}$ powder by a self-propagating high-temperature synthesis technique. Mater. Lett. 2004, 58, 733-738. [CrossRef]

71. Ziemnicka-Sylwester, $\mathrm{M}$. The $\mathrm{Cu}$ matrix cermets remarkably strengthened by $\mathrm{TiB}_{2}$ "in situ" synthesized via self-propagating high temperature synthesis. Mater. Des. 2014, 53, 758-765. [CrossRef]

72. Yu, Z.; Zhu, H.; Huang, J.; Li, J.; Xie, Z. Processing and characterization of in-situ ultrafine TiB 2 -Cu composites from Ti-B-Cu system. Powder Technol. 2017, 320, 66-72. [CrossRef] 